\title{
Feeding Female Growing Rats Different Sources of Omega-3 Polyunsaturated Fatty Acids Affects Lung Fatty Acid Composition and Gene Expression
}

\author{
Maria L. Dalzot \\ West Virginia University
}

Follow this and additional works at: https://researchrepository.wvu.edu/etd

\section{Recommended Citation \\ Dalzot, Maria L., "Feeding Female Growing Rats Different Sources of Omega-3 Polyunsaturated Fatty Acids Affects Lung Fatty Acid Composition and Gene Expression" (2012). Graduate Theses, Dissertations, and Problem Reports. 413. \\ https://researchrepository.wvu.edu/etd/413}

This Thesis is protected by copyright and/or related rights. It has been brought to you by the The Research Repository @WVU with permission from the rights-holder(s). You are free to use this Thesis in any way that is permitted by the copyright and related rights legislation that applies to your use. For other uses you must obtain permission from the rights-holder(s) directly, unless additional rights are indicated by a Creative Commons license in the record and/ or on the work itself. This Thesis has been accepted for inclusion in WVU Graduate Theses, Dissertations, and Problem Reports collection by an authorized administrator of The Research Repository @ WVU. For more information, please contact researchrepository@mail.wvu.edu. 
Feeding Female Growing Rats Different Sources of Omega-3 Polyunsaturated Fatty Acids Affects Lung Fatty Acid Composition and Gene Expression

\author{
Maria L. Dalzot
}

Thesis submitted to the Davis College of Agriculture, Forestry and Consumer Sciences at West Virginia University in partial fulfillment of the requirements for a degree of

\author{
Master of Science \\ in \\ Nutritional and Food Science \\ Janet C. Tou, PhD, Chair \\ Vagner Benedito, PhD \\ Joseph Moritz, PhD
}

Division of Animal and Nutritional Sciences

Morgantown, West Virginia 2012

Keywords: Omega-3 Fatty Acids, Omega-6 Fatty Acids, EPA, DHA, Fish Oil, Krill Oil, Flaxseed Oil, Menhaden Oil, Salmon Oil, Tuna Oil, Oxidative Stress, Eicosanoids

Copyright 2012 Maria L. Dalzot 


\title{
ABSTRACT \\ Feeding Female Growing Rats Different Sources of Omega-3 Polyunsaturated Fatty Acids Affects Lung Fatty Acid Composition and Gene Expression
}

\author{
Maria L. Dalzot
}

Justification: The lungs are constantly exposed to oxidative stress and inflammation which increase the risk of lung damage. Omega-3 polyunsaturated fatty acids (n-3 PUFAs), found in different dietary sources, regulate the expression of various genes involved in eicosanoid production and oxidative stability.

Objective: to determine whether providing different sources of n-3 PUFAs will affect the fatty acid composition, inflammation and oxidation in the lungs of growing rats.

Methods: Growing (age 28 d) Sprague-Dawley rats were randomly assigned ( $n=10$ /group) to diets consisting of either corn oil (CO) or n-3 PUFA rich flaxseed (FO), krill (KO), salmon (SO) or tuna (TO) oil for 8 weeks. Diet and tissue fatty acid composition was analyzed by gas chromatography. The enzymes involved in eicosanoid synthesis, 5-lipoxygenase (5-LOX) and cyclooxygenase II (COX II), and the antioxidant enzymes, catalase (CAT), glutathione peroxidase (GSH-Px) and superoxide dismutase 1 (SOD1), were determined using real-time polymerase chain reaction.

Results: Rats fed FO, with the highest alpha-linolenic acid (ALA, 18:2n-3) content, had the highest $(P<0.001)$ lung ALA deposition. Rats fed KO, with the highest eicosapentaenoic acid (EPA, 20:5n3) content, had the highest $(P<0.001)$ lung EPA deposition compared to all diet groups, except SO-fed rats. Rats fed TO, with the highest docosahexaenoic acid (DHA, 22:6n-3) content, had the highest $(P<0.001)$ lung DHA deposition compared to rats fed $\mathrm{CO}$ or FO. The relative expression of 5-LOX was significantly up-regulated $(P=0.007)$ in rats fed $\mathrm{FO}$ compared to $\mathrm{CO}$-fed rats. Expression of the antioxidant defense enzyme, SOD1 was down-regulated $(P=0.01)$ in TO-fed rats compared to rats fed CO. Dietary TO has an EPA/DHA ratio of 1:2 and had a higher $(P<0.001)$ lung DHA content compared to rats fed CO.

Significance: The fatty acid composition of the lungs reflected dietary intake. The increase in $\omega-3$ PUFAs in lung tissue may affect the risk of lung damage, and in turn, susceptibility to lung diseases by altering gene expression of inflammation and oxidative stability. 


\section{ACKNOWLEDGMENTS}

* Thank you to Dr. Janet Tou for advising me the past 6 years. It is because of her constant patience, guidance and expertise that have allowed me to excel in my academic career.

Thank you to Dr. Vagner Benedito for inviting me into his lab and teaching me molecular techniques that compelled me to reach far beyond my comfort zone.

* Thank you to Joseph Gigliotti for taking me under his wing during my first year as a graduate student and showing me the ins and outs of lab work.

* Thank you to the undergraduates, Adam Knecht and Nainika Nanda for dedicating their time to assisting with the RT-qPCR.

* Thank you to Dr. Joseph Moritz for agreeing to participate in my committee and giving me his much valued advice.

* Thank you to Dr. Hillar Klandorf for his constant support and for pushing me to excel.

* Thank you to the Davis College for being like family to me during my collegiate experience at West Virginia University.

Thank you to my family and friends for their constant love, patience and support. 


\section{TABLE OF CONTENTS}

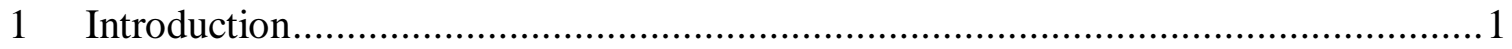

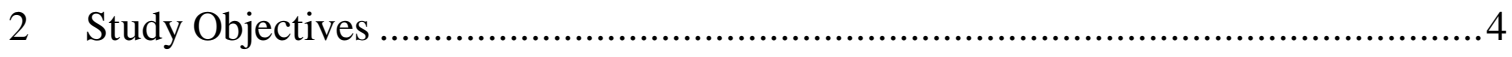

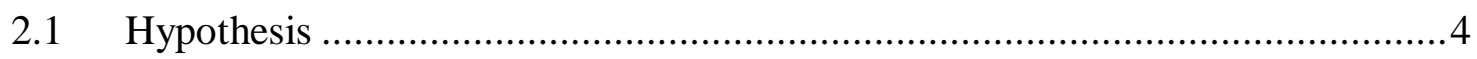

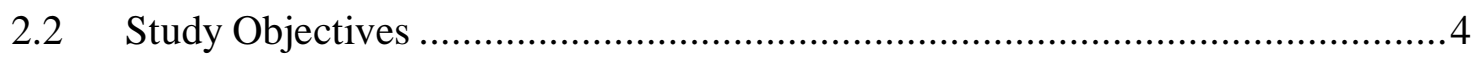

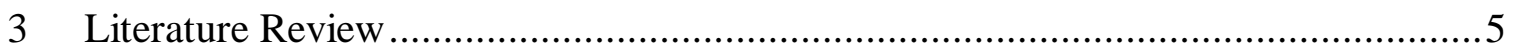

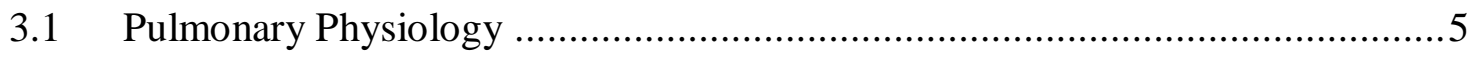

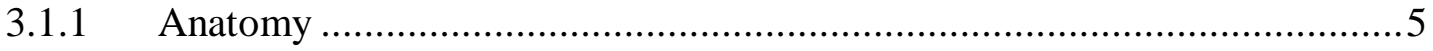

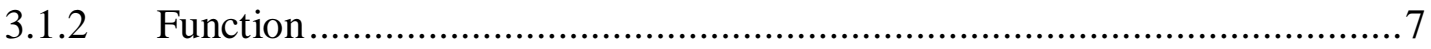

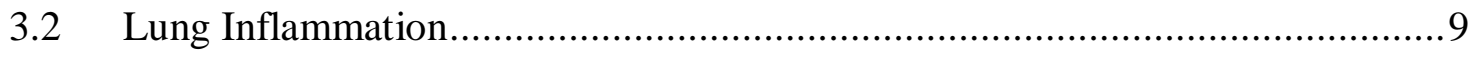

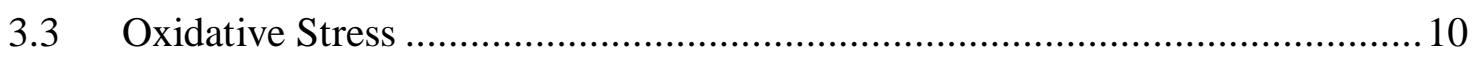

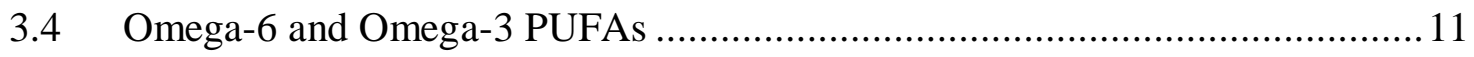

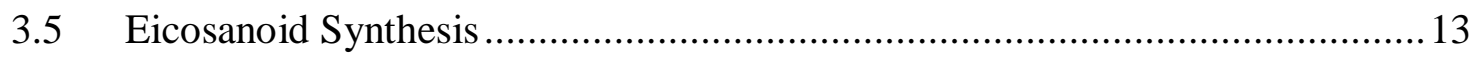

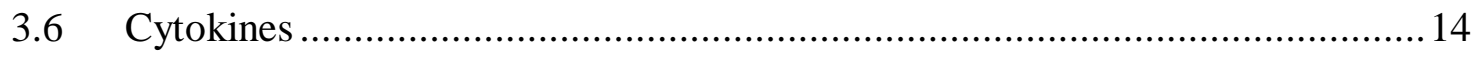

3.7 Omega-3 Fatty Acids and Respiratory Inflammation ...................................15

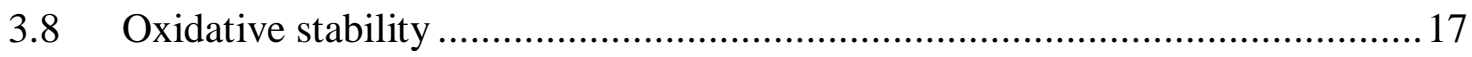

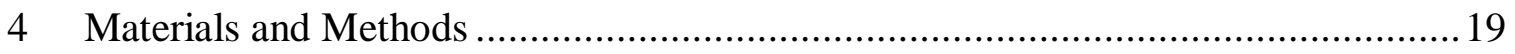

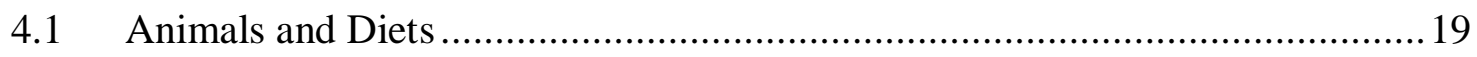

4.2 Lung Fatty Acid Composition ……………............................................22

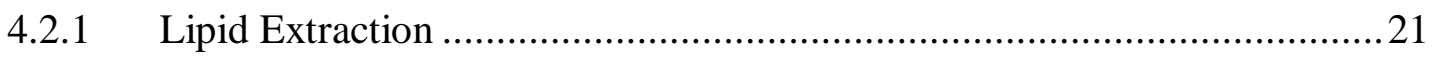

4.2.2 Fatty Acid Methylation ...................................................................2

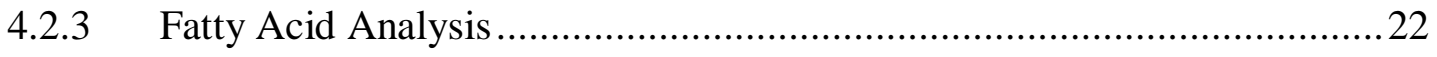

4.3 RNA Isolation and Gene Expression ……………...................................22

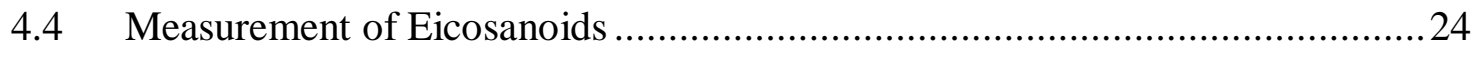

4.5 Measurement of Oxidative Stability ...........................................................2 
4.6 Statistical analyses ........................................................................ 25

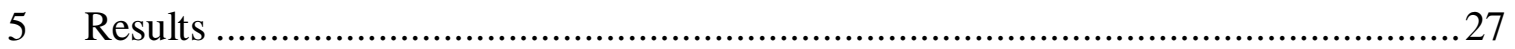

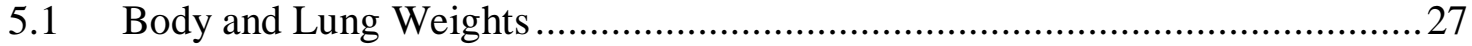

5.2 Lung Lipids and Fatty Acid Composition ...............................................22

5.3 Eicosanoid Metabolism .................................................................... 28

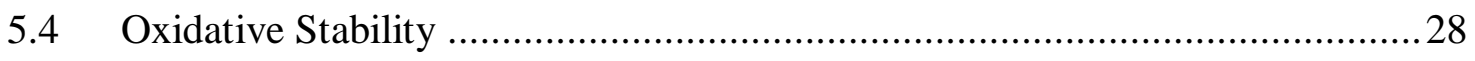

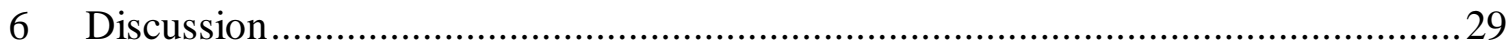

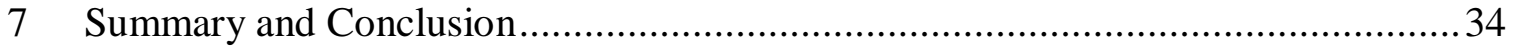

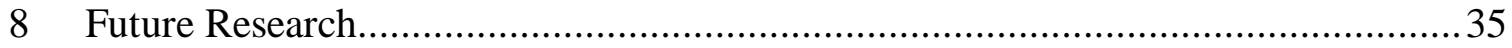

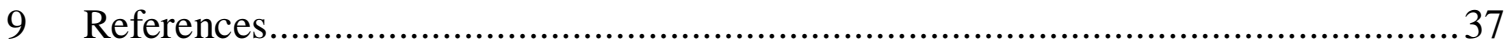




\section{LIST OF TABLES}

\section{Table 1. Diet Composition}

Table 2. Fatty Acid Profile of Dietary Oils

Table 3. Body Weight, Weight Gain and Food Intake of Growing Female Rats Fed Different Sources of Omega-3 Polyunsaturated Fatty Acids

Table 4. Fatty Acid Composition in Lungs of Growing Female Rats Fed Different Sources of Omega-3 Polyunsaturated Fatty Acids

Table 5. Oxidative Stability Measurements in Growing Rats Fed Different Sources of Omega-3 Polyunsaturated Fatty Acids 


\section{LIST OF FIGURES}

Figure 1.

A) Absolute lung weights (g) of female rats fed different sources of omega-3 polyunsaturated fatty acids.

B) Relative lung weights $(\mathrm{mg} / 100 \mathrm{~g})$ in the lungs of female rats fed different sources of omega-3 polyunsaturated fatty acids.

Figure 2. Percent lipid in the lungs of female rats fed different sources of omega-3 polyunsaturated fatty acids.

Figure 3. The effect of feeding growing female rats fed different sources of omega-3 polyunsaturated fatty acids on gene expression of A) 5-lipoxygenase (5-LOX) and B) cyclooxygenase II (COX II).

Figure 4.

A) Urine $\mathrm{TXB}_{2}$ metabolite concentrations $(\mathrm{pg} / \mathrm{mL})$ in growing female rats fed different sources of omega-3 polyunsaturated fatty acids.

B) Urine $\mathrm{PGE}_{2}$ metabolite concentrations (ug/d) in young growing rats fed different sources of omega-3 polyunsaturated fatty acids.

Figure 5. The effect of feeding growing female rats fed different sources of omega-3 polyunsaturated fatty acids on gene expression of A) catalase (CAT), B) glutathioneperoxidase (GSH-Px) and C) superoxide dismutase 1 (SOD1). 


\section{LIST OF ABBREVIATIONS}

\begin{tabular}{|c|c|}
\hline 5- LOX & 5- lipoxygenase \\
\hline$\omega-3$ & Omega-3 \\
\hline$\omega-6$ & Omega-6 \\
\hline AA & Arachidonic Acid \\
\hline ALA & $\alpha$-Linolenic Acid \\
\hline ANOVA & Analysis of Variance \\
\hline ARDS & Acute Respiratory Distress Syndrome \\
\hline $\mathrm{CO}$ & Corn Oil Diet \\
\hline COPD & Chronic Obstructive Pulmonary Disease \\
\hline COX II & Cyclooxygenase II \\
\hline $\mathrm{ddH}_{2} \mathrm{O}$ & De-ionized/distilled Water \\
\hline DHA & Docosahexaenoic Acid \\
\hline EDTA & Ethylenediaminetetraacetic acid \\
\hline EPA & Eicosapentaenoic Acid \\
\hline FAME & Fatty Acid Methyl Ester(s) \\
\hline FO & Flaxseed Oil Diet \\
\hline GAPDH & Glyceraldehyde 3-Phosphate Dehydrogenase \\
\hline GSH-Px & Glutathione Peroxidase \\
\hline $\mathrm{H}_{2} \mathrm{O}$ & Water \\
\hline $\mathrm{H}_{2} \mathrm{SO}_{4}$ & Sulfuric Acid \\
\hline IL-6 & Interleukin-6 \\
\hline $\mathrm{KO}$ & Krill Oil Diet \\
\hline
\end{tabular}




\begin{tabular}{|c|c|}
\hline $\mathrm{LTB}_{4}$ & Leukotriene $\mathrm{B}_{4}$ \\
\hline LA & Linoleic Acid \\
\hline Min & Minutes \\
\hline MO & Menhaden Oil Diet \\
\hline $\mathrm{n} / \mathrm{a}$ & Not Applicable \\
\hline $\mathrm{Na}_{2} \mathrm{SO}_{4}$ & Sodium Sulfate \\
\hline ND & Not Detectable \\
\hline $\mathrm{PGE}_{2}$ & Prostaglandin E2 \\
\hline PL & Phospholipid \\
\hline PUFA & Polyunsaturated Fatty Acid(s) \\
\hline Rf & Retention Factor \\
\hline ROS & Reactive Oxygen Species \\
\hline RT & Reverse Transcriptase \\
\hline RT-qPCR & Reverse Transcriptase-Polymerase Chain Reaction \\
\hline SEM & Standard Error of the Mean \\
\hline SFA & Saturated Fatty Acid(s) \\
\hline SO & Salmon Oil Diet \\
\hline SOD & Superoxide Dismutase \\
\hline TBA & Thiobarbituric Acid \\
\hline TBARS & Thiobarbituric Acid Reactive Substances \\
\hline TG & Triglyceride \\
\hline TLC & Thin Layer Chromatography \\
\hline TNF- $\alpha$ & Tumor Necrosis Factor-Alpha \\
\hline
\end{tabular}


TO

$\mathrm{TXA}_{2}$
Tuna Oil Diet

Thromboxane A2 


\section{INTRODUCTION}

The long-chain omega-3 polyunsaturated fatty acids ( $\omega-3$ PUFAs), primarily

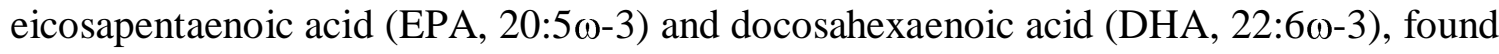
in fatty fish and fish oils, have been extensively studied for their protective effects in cardiovascular disease as well as for their roles in growth and development (Egert, 2009; Yang, 1994). Eicosanoids derived from EPA and DHA have also been shown to be involved in homeostatic regulation of the lungs and to play a role in respiratory diseases (Craig-Schmidt et al., 1987). The prevalence of respiratory diseases among infants and adults is increasing (Christie et al., 1999). Therefore, it is important to determine novel interventions that have the ability to prevent or modify the course of lung disease. A potential area is the contribution of dietary consumption of $\omega-3$ PUFAs for the prevention of lung inflammation and disease.

The $\omega-3$ PUFAs have been shown to reduce inflammatory effects through competitive inhibition of the enzymes necessary for the production of pro-inflammatory eicosanoids from the omega-6 polyunsaturated fatty acids ( $\omega-6$ PUFAs). The $\omega-6$ PUFA, arachidonic acid (AA, 20:4 $\omega-6$ ) is the precursor to the 2 and 4-series eicosanoids which include thromboxane $\mathrm{A}_{2}\left(\mathrm{TXA}_{2}\right)$ and the pro-inflammatory prostaglandin $\mathrm{E}_{2}\left(\mathrm{PGE}_{2}\right)$ and leukotriene $\mathrm{B}_{4}\left(\mathrm{LTB}_{4}\right)$. EPA competes for the same cyclooxygenase II (COX II) enzyme as the $\omega-6$ PUFA, AA. Thereby, increasing dietary EPA reduces the synthesis of 2-series $\mathrm{PGE}_{2}$ and increasing the synthesis of the less reactive 3-series prostaglandins and thromboxanes. Previous studies have focused on the eicosanoids produced by the cyclooxygenase pathway. However, leukotrienes, products from the 5- lipoxygenase (5LOX) pathway, also warrant study because leukotrienes are known to be elevated in 
respiratory diseases such as asthma and cystic fibrosis (O’Driscoll, 1982). The $\omega-3$

PUFA, EPA, competes for the same 5-LOX enzyme as the $\omega-6$ PUFAs, AA. Thereby, increasing dietary EPA reduces the synthesis of 4-series leukotrienes and increases the synthesis of the less reactive 5-series leukotrienes.

Craig-Schmidt et al. (1987) found that it was possible to modulate lung prostanoids (prostaglandins and thromboxanes) by manipulating the $\omega-6 / \omega-3$ ratio in the diet of broiler chickens. The production of 2-series eicosanoids was decreased when dietary alpha-linolenic acid (ALA, 18:3 $\omega-3$ ), provided as flaxseed oil, was increased. Fritsche and Johnston (1990) demonstrated that feeding a diet rich in ALA to rodents resulted in reducing lung and extra-pulmonary metastases.

Flaxseed is the richest source of ALA (Cunnane, 1995); however, data indicate that the biological conversion of ALA to the $\omega-3$ PUFAs, EPA and DHA, is low (Simopoulos, 2008). Fish oils are rich sources of pre-formed EPA and DHA. Thus, flaxseed may elicit less biological activity than fish oils rich in EPA and DHA. However, fish oils differ in the amount and ratio of EPA and DHA (Tou et al., 2011). Additionally, in fish and plant sources, the $\omega-3$ PUFAs are mainly associated with triglycerides. However, krill oil fatty acids are mainly in the form of phospholipids (Gigliotti et al., 2010). This is significant because $\omega$-3 PUFAs associated with phospholipids may be more bioavailable and more stable against lipid peroxidation than triglycerides (Song et al., 2000).

Alterations in the fatty acid composition may have significant effects on cell membranes. However, due to numerous double bonds, $\omega-3$ PUFAs are also susceptible to lipid peroxidation and may cause a decrease in the concentration of antioxidants in 
animal tissues (Song et al., 2000). Therefore, oxidative stability is also important to consider before recommending supplementation of the diet with different sources of $\omega-3$ PUFAs. The effect of $\omega-3$ PUFA intake on lipid peroxidation has produced inconsistent results of increased oxidation (Song et al., 2000; Song and Miyazawa, 2001; Yuan and Kitts, 2003), no effect on oxidation (Calviello, 1997) and even decreased oxidation (Demoz et al., 1992).

The lungs are particularly susceptible to oxidative stress due to constantly being exposed to inhaled air (Wright, 2003). Several pulmonary diseases have been linked to an imbalance in the oxidant and antioxidant state in the lungs resulting in severe pulmonary inflammation (Lang et al., 2002). The objective of the study was to determine whether providing different sources of $\omega$-3 PUFAs will affect fatty acid composition, inflammation and oxidative stability in the lungs of growing female rats. 


\section{STUDY OBJECTIVES}

\subsection{Hypothesis}

Consuming diets rich in $\omega-3$ PUFAs will alter lung fatty acid composition and decrease the gene expression of the pro-inflammatory enzymes involved in eicosanoid synthesis without increasing oxidative stress.

\subsection{Study Objectives}

1. To determine the effect of feeding different sources of $\omega-3$ PUFAs on lung lipid composition in growing female rats.

2. To determine the effect of feeding different sources of $\omega-3$ PUFAs on expression of the mediators of inflammation, COX II and 5-LOX, in the lungs of growing female rats.

3. To determine the effect of feeding different sources of $\omega-3$ PUFAs on oxidative stability in the lungs of growing female rats. 


\section{LITERATURE REVIEW}

\subsection{Pulmonary Physiology}

The respiratory system is a highly integrated system that is composed of the lungs, conducting airways that lead into the lungs and the respiratory muscles of the thorax. These structures work together to deliver oxygen from the environment into the tissues.

\subsubsection{Anatomy}

According to the American Lung Association, the human thoracic cavity is divided into two chambers that hold the right and left lung by the mediastinum, where vital organs including the heart, thymus gland, the trachea, the esophagus and the lymph nodes are located. The human lung is between 25 and 30 centimeters long and is covered by a protective membrane called the visceral pleura (Hlastala and Berger, 2001). The right lung is slightly larger than the left lung and has three lobes (upper, middle and lower) that are separated into ten segments. The left lung is smaller because the heart is on the left and is divided into two lobes (upper and lower) composed of nine segments. In contrast, a rat has five lung lobes: one left lobe and four right lobes (Suckow et al., 2006). However, the anatomical structure of a rat's upper respiratory system is analogous to that of a typical mammal.

As described by Hlastala and Berger (2001), mammalian airways begin in the nasal passage, which has three major functions: trap inhaled particles, heat and humidify inspired air. The passage then opens into the 
pharynx and air passes through the larynx and the trachea, the largest airway. The trachea has C-shaped discs made out of cartilage that function to keep the airways open. The airways proceed in a branching pattern dividing the trachea into two main branches, the right and left bronchi, each entering the right and left lung, respectively. The bronchus in each lung continues to branch into more narrow airways termed bronchioles. The terminal bronchioles have smooth muscles rather than cartilage covering their walls. This allows for adjustment of lung diameter. During asthma, constriction of these terminal bronchioles in response to an allergen decreases the airway diameter. After the terminal bronchioles, the function of the respiratory system transitions from conduction to gas exchange (Hlastala and Berger, 2001).

As reviewed by Hlastala and Berger (2001), the functional unit of the respiratory system is called the acinus, the smallest collection of parts that will perform the basic function of the system, i.e. gas exchange. The acinus is broken up into three parts: the respiratory bronchioles, the alveolar ducts and the alveolar sacs. The respiratory bronchioles have sparse alveoli on their surface. The alveolar ducts are tubes where the walls are completely covered in alveoli. The alveolar sacs are the terminal component of the bronchial tree. The alveolar sacs are accumulations of alveoli with no smooth muscle or connective tissue. The walls of the alveoli have a diameter of about $0.1 \mu \mathrm{m}$ and a large surface area to provide 
for easy gas exchange between the air in the alveoli and the blood in the pulmonary capillaries (Hlastala and Berger, 2001).

The cells of the alveoli have a layer of water that forms a lining on the cell and causes a high surface tension. To pull air into the lungs, the air sacs must be expanded. However, due to the high surface tension of the small alveoli, a surface active agent must be added to reduce the surface tension of the alveoli. The Type II alveolar cells produce the surface active agent known as surfactant. Surfactant is made up of 70$80 \%$ phospholipids, primarily dipalmitoylphosphatidylcholine (Nkadi et al., 2009). In many mammals, surfactant is composed of mostly monounsaturated phospholipids. In the rat, surfactant has high polyunsaturated phospholipid content (Suckow et al., 1996). Survival depends on producing surfactant in the lungs.

\subsubsection{Function}

Nelms et al. (2007) described that the primary function of the lungs is to deliver sufficient amounts of oxygen from the external environment into the tissues. This involves a need for the arterial blood to have enough oxygen to meet the body's metabolic demands and enough energy for the movement of gas into and out of the lungs. Gas exchange occurs via passive diffusion. The barrier between gas and blood has a large surface area and is extremely thin so that gas exchange can take place under severe demands of oxygen. 
The human lungs undergo a period of growth and maturation during the first two decades of life. By 10-12 years of age the maximal number of alveoli is attained. Full maturation of the respiratory system is achieved by age 20 for females and 25 for males (Nelms et al., 2007). In the rat, lungs mature over a period of two years (Harding and Pinkerton, 1982).

Aging is associated with a progressive decrease in lung function; however, unless affected by disease, the lungs are capable of providing adequate gas exchange during the entire lifespan (Nelms et al., 2007). The major functional changes are an increase in lung compliance, a decrease in chest wall compliance (increased stiffness) and reduction in respiratory muscle strength (Harding and Pinkerton, 1982).

Removing carbon dioxide $\left(\mathrm{CO}_{2}\right)$ that is produced by cellular metabolism is another major gas exchange function of the respiratory system. $\mathrm{CO}_{2}$, like oxygen, moves by diffusion from the cells to the capillaries where it is transported via the right heart to the lungs for release into the atmosphere during exhalation (Hlastala and Berger, 2001).

The lungs are also important in the body's defense against infection and other destructive environmental factors. The nose is the first line of defense against inhaled harmful materials. The lungs provide the second line of defense. The cells that line the trachea, bronchi and bronchioles contain cilia which beat with a rhythm that is fast and forceful enough to propel mucus and unwanted cells upward toward the pharynx where they 
can be coughed out or swallowed. The epithelial surface of the alveoli contains macrophages or scavenger cells that engulf and destroy inhaled bacteria (Nelms et al., 2007).

Surfactant also has a role in lung function as a host defense mechanism. According to Wright (2003), the host's response to inflammation may be dependent upon the relative proportions of the surfactant phospholipids within the air space. The surfactant-associated proteins, SP-A and SP-D, bind to a variety of pathogens. The surfactantassociated proteins enhance uptake by macrophages and may influence the production and secretion of inflammatory cytokines and superoxide radicals from inflammatory cells (Wright, 2003). Studies in which various bacteria and viruses were administered to SP-A-deficient mice show an enhanced pulmonary inflammatory reaction and an increased release of the proinflammatory cytokines, tumor necrosis factor-alpha (TNF- $\alpha$ ) and interleukin-6 (IL-6) into the airways (Spragg and Lewis, 2001).

\subsection{Lung Inflammation}

Inflammation has an influential role in the pathogenesis of respiratory diseases such as pulmonary fibrosis, chronic obstructive pulmonary disease (COPD) and acute respiratory distress syndrome (ARDS). The rat model mimics many features of human asthma and acute lung injury. Therefore, many models of lung disease have used rat lungs and/or rat cells (National Heart, Lung, and Blood Institute, 1999). 
Almost all types of pulmonary disease can be classified as either restrictive pulmonary disease or obstructive pulmonary disease. Restrictive pulmonary diseases cause an increase in the elastic resistance or decreased compliance of the lungs. Under normal conditions, the lungs and the thorax are compliant. However, there is decreased compliance in a diseased state. The classic example of a disease that decreases lung compliance is pulmonary fibrosis. The tissues of the lungs become fibrous, scarred and inelastic, making it more difficult to inflate the lungs and the amount of work to breathe greater (National Heart, Lung, and Blood Institute, 1999).

Obstructive pulmonary diseases are classified as asthma, chronic bronchitis and emphysema. The chronic inflammation in these diseases causes an increase in airway hyper-responsiveness, which is distinguished by a heightened sensitivity of the airways' ability to narrow after being exposed to a constrictor agonist (O'Byrne, 2003). Many pulmonary diseases have been linked to oxidative tissue injury in the lungs (Kinnula and Crapo, 2003).

\subsection{Oxidative Stress}

Oxidative stress is a state of imbalance between the body's antioxidant and pro-oxidant mechanisms that results in high levels of reactive oxygen species (ROS). Examples of ROS include, but are not limited to, superoxide, hydrogen peroxide, hydroxyl radicals and nitric oxide. As levels of ROS rise, damage can result due to enzyme inactivation, DNA destruction or membrane damage. Infections and inflammation can trigger oxidative stress (McKee and McKee, 2009; Lang et al, 2002). 
The lungs are particularly susceptible to oxidative stress due to its unique structure. The lungs reside at the border of the internal environment and the external environment, and have a vast surface area that is susceptible to pathogens, allergens and pollutants found in the 11,000 liters of daily inhaled air (Wright, 2003). Several pulmonary diseases have been linked to an imbalance in the oxidant and antioxidant state in the lungs resulting in severe pulmonary inflammation (Lang et al., 2002).

Patients suffering from COPD, ARDS and asthma have been shown to have significantly lower plasma levels of the antioxidants vitamin E, vitamin $\mathrm{C}$, beta-carotene and selenium (Kinnery et al., 2006), as well as plasma ascorbate and ubiquinol (Lang et al., 2002). Lang et al., (2002) found a decrease in pulmonary inflammation with a reduced production of oxidants when an enteral formula supplemented with EPA was administered to ARDS patients. Therefore, the next sections will discuss dietary fatty acids and their potential antiinflammatory role in the lungs and oxidative stability.

\subsection{Omega-6 and Omega-3 PUFAs}

It has been estimated that the present Western diet has a $\omega-6$ to $\omega-3$ ratio of 15-20:1. This is significantly higher than the recommended serum 4:1 ratio suggested for general health (Simopoulos, 2008).

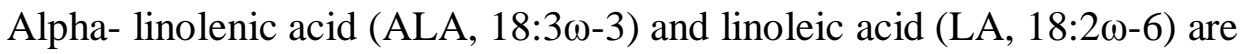
essential fatty acids. Essential is defined as the inability of the human body to synthesize the nutrients required for proper physiological functioning. Due to the absence of the desaturase enzymes, delta 12 and 15 desaturase required for de 
novo synthesis, humans must obtain ALA and LA through the diet (Ratnayake and Galli, 2009). LA can be found in most vegetable oils. Rich food sources of ALA include soybean oil, canola oil and particularly, flaxseed oil (Cunnane, 1995). Therefore, the proposed study will use corn oil as a source of LA and flaxseed as a source of ALA.

The essential fatty acid, LA, may be converted to long-chain $\omega-6$ PUFA,

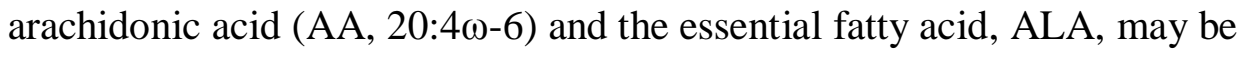
converted to the long chain $\omega$-3 PUFA, eicosapentaenoic acid (EPA, 20:5 $\omega$-3) and

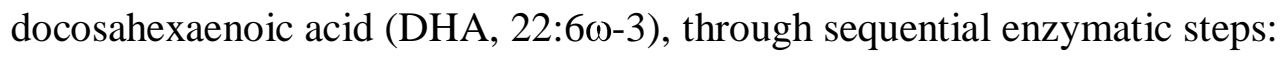
elongation, desaturation, and $\beta$-oxidation (Fig. 1). EPA and DHA can be synthesized by mammals from ALA; however, conversion of dietary ALA into EPA and DHA is limited because the efficiency of $\omega-3$ LC-PUFA synthesis decreases down the cascade of ALA conversion (Galli and Calder, 2009). EPA and DHA are readily available from fatty fish. Salmon, tuna, menhaden and krill oil are commercially available sources of $\omega-3$ PUFAs supplements (Tou et al., 2011).

EPA and DHA play a vital role in many metabolic processes. Many of EPA's metabolic effects are produced through conversion to eicosanoids. 


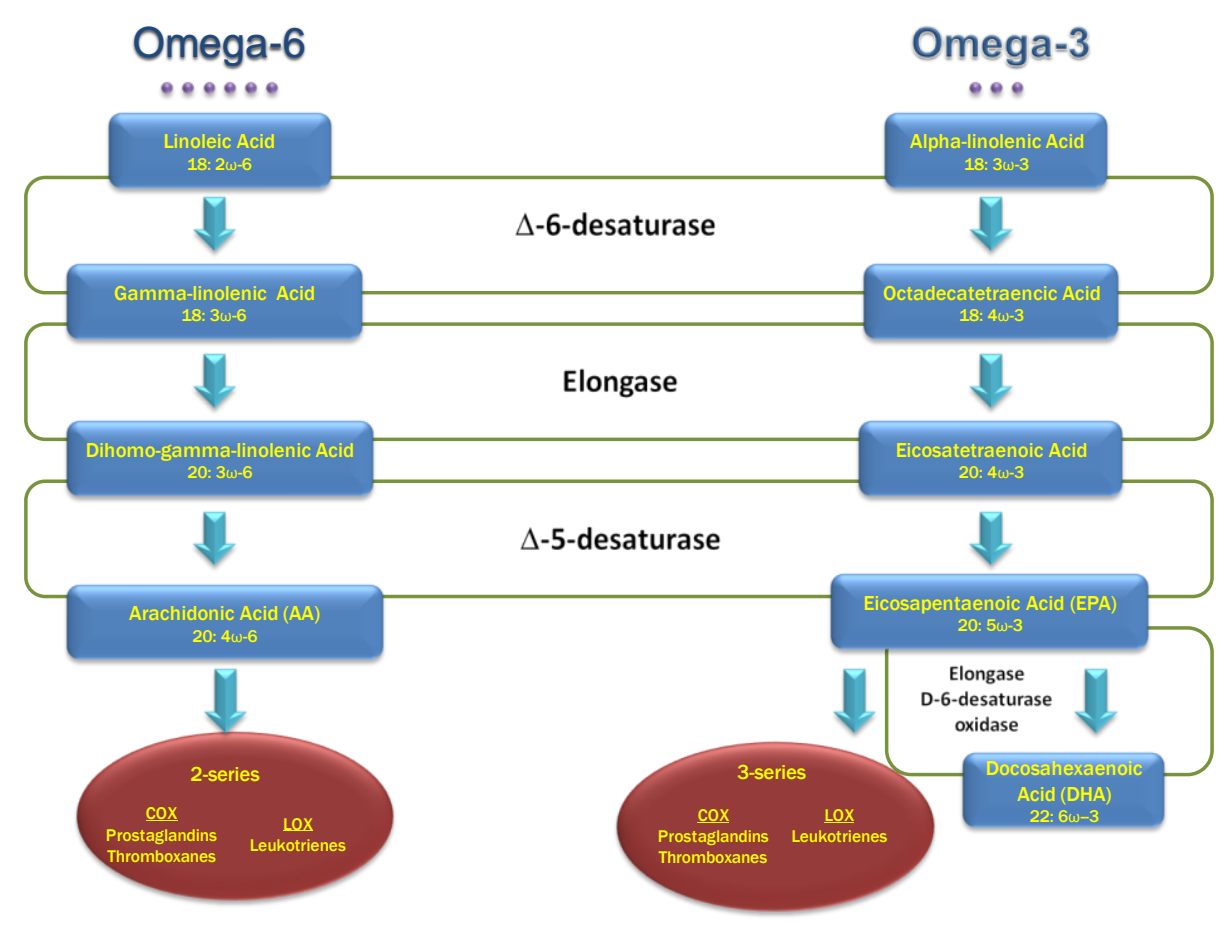

Figure 1: Essential Fatty Acid Metabolic Pathway

\subsection{Eicosanoid Synthesis}

Eicosanoids are hormone-like signaling molecules derived from the oxidation of the twenty-carbon $\omega-3$ PUFAs, AA and EPA. Eicosanoids mainly function in inflammation or immunity, and act as messengers in the central nervous system. The $\omega-6$ eicosanoids are generally pro-inflammatory, whereas the $\omega-3 \mathrm{~s}$ are less reactive. Therefore, the amounts and balance of $\omega-6$ and $\omega-3$ PUFAs affect the body's eicosanoid concentration and in turn, the different eicosanoids affect normal lung physiology as well as influencing risk for lung diseases.

There are three main types of eicosanoids: prostaglandins, thromboxanes and leukotrienes. The thromboxanes play a role in vasoconstriction, and the prostaglandins and leukotrienes play a role in inflammation. The series- 2 
prostaglandins $\left(\mathrm{PGE}_{2}\right)$ and series-4 leukotrienes $\left(\mathrm{LTB}_{4}\right)$ derived from AA are involved in vasoconstriction and the synthesis of mediators of inflammation in response to physiological stress. The series-3 prostaglandins ( $\left.\mathrm{PGE}_{3}\right)$ and series-5 leukotrienes $\left(\mathrm{LTB}_{5}\right)$ derived from EPA are less physiologically potent than eicosanoids derived from AA (Simopoulos et al., 1999). Therefore, EPA competing for the same enzymes as AA reduces synthesis of pro-inflammatory $\mathrm{PGE}_{2}$ and increases the synthesis of less inflammatory $\omega-3$ eicosanoids.

The reduced inflammatory effects of $\omega-3$ fatty acids were originally recognized as properties of the eicosanoids produced from the cyclooxygenase and 5-lipoxygenase pathways. However, more recent studies have investigated reduced production of cytokines as a potential mechanism (Blok et al., 1996).

\subsection{Cytokines}

Cytokines are small proteins that are involved in intracellular communication and regulation of immunity. During acute bacterial lung infection, the release of cytokines promotes the recruitment and activation of macrophages and neutrophils. Although these cells are important in host defense against pathogens, dysregulation of immune response can cause local tissue damage because the cells produce free radicals and ROS (Cheng et al., 2007; Tiesset et al., 2009).

TNF- $\alpha$ is considered a pro-inflammatory cytokine produced from phagocytic cells that mediate the host's response to inflammatory stimuli (Blok et al, 1996). In a study conducted on inflammatory markers detected in COPD, a diet high in the $\omega-3$ PUFA, ALA, decreased production of TNF- $\alpha$ which produces 
a variety of inflammatory mediators that affect the bronchial epithelial cells (Matsuyama et al., 2005).

The anti-inflammatory properties of $\omega-3$ PUFAs are partially mediated by interaction with peroxisome proliferator-activated receptors (PPAR). PPAR are expressed in various types of cells that play important roles in inflammation and immunity. PPAR $\alpha$ is abundant in macrophages, monocytes and endothelial cells, and PPAR $\gamma$ is abundant in alveolar epithelial cells and the bronchial sub-mucosa (Simon et al., 2006). Ligands of PPAR $\alpha$ and PPAR $\gamma$ inhibit the expression of pro-inflammatory genes in response to cytokine activation. This effect is dependent upon transcription factor nuclear factor kappa B (NF-кB) activation (Tiesset et al., 2009). NF-кB is a critical regulator of innate immune responses, including the pro-inflammatory cytokines (Uddin and Levy, 2010). Cheng et al. (2007) indicated that inhibition of NF- $\mathrm{KB}$ activation in airway epithelium reduces lung inflammation and injury induced by the gram-negative bacteria lipopolysaccharide. The $\omega-3$ PUFAs influence the regulation of eicosanoids and cytokines; therefore, the next section discusses the role of $\omega-3$ fatty acids on lung inflammation.

\subsection{Omega-3 Fatty Acids and Respiratory Inflammation}

The relationship between $\omega-3$ PUFAs and pulmonary disease was suggested by the observation that Inuits living in Greenland had a lower prevalence of bronchitis and asthma than Inuits living in Denmark (Horrobin, 1987). This observation was hypothesized to be due to the consumption of large quantities of oily fish that are rich in the $\omega-3$ fatty acids, EPA and DHA by the 
Greenland Inuits (Horrobin, 1987). The eicosanoids derived from EPA and DHA may reduce airway inflammation and bronchoconstriction, and thus reduce the risk of respiratory disease.

The derivatives from the lung's eicosanoids play an important role in pulmonary function. Evidence has suggested that eicosanoids have an influence on pulmonary edema, impaired gas exchange and immune responses associated with lung injuries. Exposure to allergens has been shown to stimulate $\mathrm{LTB}_{4}$ release from tracheal epithelium and alveolar macrophages, which act as potent activators of neutrophils (Meydani et al., 1992). Matsuyama et al. (2005) found that nutritional support with an ALA-rich diet decreased serum and sputum levels of $\mathrm{LTB}_{4}$.

There was a decreased production of $\mathrm{PGE}_{2}$ and $\mathrm{TXB}_{2}$ when dietary ALA supplied as flaxseed oil was added to the diets of chickens (Craig-Schmidt et al., 1987). Chickens were chosen as the animal model for dietary manipulation of lung eicosanoids based on a previous report that indicated chickens fed diets deficient in essential fatty acids developed pulmonary diseases (Hopkins et al., 1963).

PUFAs may mitigate the development of bronchopulmonary dysplasia (BPD), the most common type of chronic lung injury seen in pre-term infants receiving oxygen therapy. In the pathogenesis of BPD, neutrophils release ROS and proteases, which eventually lead to pulmonary fibrosis. Studies have shown that rats subjected to hypoxia and then fed fish oil had less pulmonary fibrosis by modifying lung injury due to hyperoxia (D’Ambola et al., 1991). 
Information concerning dietary manipulation of pulmonary eicosanoids is

limited. Therefore, our research determined if dietary $\omega$-3 PUFAs have the potential to act as modulators of eicosanoid biosynthesis in the respiratory system. However, before $\omega-3$ PUFAs are added to the diet for health benefits, it is important to assess any potential risks associated with increased $\omega-3$ consumption.

\subsection{Oxidative stability}

The effect of $\omega$-3 PUFA intake on lipid peroxidation has produced inconsistent results of increased oxidation (Song et al., 2000; Song and Miyazawa, 2001; Yuan and Kitts, 2003), no effect on oxidation (Calviello, 1997) and even decreased oxidation (Demoz et al., 1992). DHA and EPA are highly susceptible to peroxidation due to their double bonds. DHA is more readily oxidized than ALA, LA and AA (Song et al., 2000). Song et al. (2000) found that feeding DHA-containing oil to healthy rats increased tissue DHA deposition and decreased the amount of the antioxidant, $\alpha$-tocopherol, in target membranes of the liver and kidney. These results suggest that $\omega-3$ PUFA supplementation may require addition of antioxidants to prevent tissue damage due to lipid peroxidation.

The impact of ROS may be especially important in the lungs because of its surface area and its exposure to higher oxygen levels than other tissues. The lung has several antioxidant defense systems that act to oppose destructive oxidation. Several of these antioxidants are superoxide dismutase (SOD), catalase and glutathione peroxidase (GSH-Px) (Day, 2007). According to Demoz et al. (1992), 
GSH-Px and catalase activity increased in healthy mice after gastric intubation with EPA. However, Yuan and Kitts (2003) found that GSH-Px activity decreased and lipid oxidation increased in the livers of MO-fed rats.

Because the lungs are highly susceptible to oxidation due to its physical structure and function, it is important to investigate dietary fatty acids and their potential anti-inflammatory role in the lungs and oxidative stability. 


\section{MATERIALS AND METHODS}

\subsection{Animals and Diets}

All animal procedures used in this study conformed to the National Research Council (NRC) Guide for the Care and Use of Laboratory Animals (NRC, 1996). The protocol for this study was approved by the Institutional Animal Care and Use committee at West Virginia University. Growing (age 28 days) female Sprague-Dawley rats $(n=60)$ were obtained from Hilltop Labs (Scottdale, PA). Growing rats were used because PUFAs are known to play a role in the normal aging process of the lung (Schwartz, 2000). Rats were individually housed in metabolic cages under conditions of controlled temperature $\left(21^{\circ} \mathrm{C}\right)$ and a 12 -h light: dark cycle. During the 7 day acclimation, all animals were given ad libitum access to deionized distilled water $\left(\mathrm{ddH}_{2} \mathrm{O}\right)$ and the American Institute of Nutrition AIN-93G diet (Harlan Teklad, WI). The AIN-93G was fed because it is a standard purified diet that meets the National Research Council (1995) recommendations for growing rats.

After a 7-day acclimation diet, the rats were randomly assigned ( $\mathrm{n}=10$ rats/group) to a high fat (12\% by weight) diet consisting of either corn oil (CO), krill oil (KO), flaxseed oil (FO), menhaden oil (MO), salmon oil (SO) or tuna oil (TO). SO, TO, KO and FO were chosen as commonly consumed sources of $\omega-3$ PUFAs. FO was chosen because it is the richest source of ALA (Cunnane, 1995). However, data suggests that the biological conversion of ALA to the $\omega-3$ LC-PUFAs, EPA and DHA, is low (Simopoulos, 2008) and thus, FO may elicit less biological activity than fish oils rich in EPA and DHA. TO was chosen for its high DHA content and salmon oil for its high EPA content. TO, SO and FO were generously donated by Jedwards International Inc. 
(Quincy, MA). MO is frequently used in research and is a $\omega-3$ PUFA source used in dietary fish oil supplements. MO was purchased from Omega Protein Inc (Houston, TX).

In fish and plant sources, the $\omega-3$ PUFAs are mainly associated with triglycerides. However, KO fatty acids are mainly in the form of phospholipids (Gigliotti et al., 2010), and was included because $\omega-3$ PUFAs associated with phospholipids have been suggested to be more bioavailable and more stable against lipid peroxidation than fatty acids associated with triglycerides (Song et al., 2000). KO was purchased from Enzymotec Ltd., Morristown, NJ.

Diet composition is shown in Table 1. Treatment diet was formulated based on the AIN-93G formulation using $12 \%$ instead of $7 \%$ lipid by weight. The $12 \%$ lipid dose was chosen because it represents the typical high-fat western diet. All diets were adjusted to have comparable amounts of kilocalories and percentage of fat. $\mathrm{CO}(0.2 \%)$ was added to $10 \% \mathrm{MO}$ or $\mathrm{KO}$ in order to meet the National Research Council recommended level of essential fatty acid, LA. Fatty acid composition of dietary oils is shown in Table 2. Rats were fed $15 \mathrm{~g}$ diet/day and provided deionized distilled water $\left(\mathrm{ddH}_{2} \mathrm{O}\right)$ ad libitum throughout the 8-week feeding study. Fresh diet was provided daily. Body weight, food intake, and water consumption were measured weekly. At the end of the 8-week study, rats were euthanized by $\mathrm{CO}_{2}$ inhalation and weighed, and tissues were dissected and weighed. Tissues were stored at $-80^{\circ} \mathrm{C}$ until analyzed. 


\subsection{Lung Fatty Acid Composition}

\subsubsection{Lipid Extraction}

Lipids were extracted from the right lung tissue according to the method by Bligh and Dyer (1959). Briefly, $48 \mu 1$ nonadecenoic acid (19:1) was added as an internal standard to weighed samples $(0.5 \mathrm{~g})$. Lung homogenate was prepared by adding weighed samples to Tris/EDTA buffer ( $\mathrm{pH} 7.4)$. The Tris retains the $\mathrm{pH}$ of the homogenate and the EDTA binds divalent cations which is important in preserving the sample. A chloroform: methanol: acetic acid (2:1:0.15 v/v/v) solution was added to the samples. Samples were centrifuged at $900 \mathrm{x} g$ for 10 min. at $10^{\circ} \mathrm{C}$ and the bottom chloroform layer collected. The collected chloroform layer was filtered through 1-phase separation filters to remove any remaining water and precipitated material. The remaining layer was mixed with chloroform: methanol $(4: 1 \mathrm{v} / \mathrm{v})$ and centrifuged at $900 \mathrm{x} g$ at $10^{\circ} \mathrm{C}$. The chloroform layer was then collected and filtered. The extracted lipid was dried under nitrogen gas.

\subsubsection{Fatty Acid Methylation}

The extracted lipid samples were transmethylated according to Fritsche and Johnston (1990). Briefly, extracted fatty acids were methylated by adding 4\% $\mathrm{H}_{2} \mathrm{SO}_{4}$ in anhydrous methanol to the dried extracted lipid samples followed by incubation in a $90^{\circ} \mathrm{C}$ water bath for $60 \mathrm{~min}$. Samples were cooled to room temperature and $3 \mathrm{~mL}$ of double distilled $\mathrm{H}_{2} \mathrm{O}$ was added to stop the reaction. Chloroform was added to the methylated samples and centrifuged at $900 \times \mathrm{g}$ for $10 \mathrm{~min}$ at $10^{\circ} \mathrm{C}$. The chloroform layer was then filtered through anhydrous 
$\mathrm{Na}_{2} \mathrm{SO}_{4}$ to remove any remaining $\mathrm{H}_{2} \mathrm{O}$. Samples were dried under nitrogen gas. Dried samples were diluted in iso-octane to a concentration of 5 mg FAME (fatty acid methyl esters)/mL iso-octane.

\subsubsection{Fatty Acid Analysis}

FAME samples were analyzed by gas chromatography (CP-3800, Varian, CA) using an initial temperature of $140^{\circ} \mathrm{C}$ held for $5 \mathrm{~min}$ and then increased $1{ }^{\circ} \mathrm{C}$ per minute to a final temperature of $220^{\circ} \mathrm{C}$. A wall-coated open tubular (WCOT) fused silica capillary column (Varian Inc., Walnut Creek, CA) was used to separate FAMEs with CP-Sil 88 as the stationary phase. Nitrogen was used as the carrier gas and total separation time was 110 min. Quantitative 37 Component FAME Sigma Mix (Supelco, Bellefonte, PA) was used as a standard to identify fatty acids. Fatty acids were quantified using peak area counts and retention time.

\subsection{RNA Isolation and Gene Expression}

Gene expression of inflammation and antioxidant enzymes were measured by isolating total RNA from lung tissue using the mirVana ${ }^{\mathrm{TM}}$ miRNA Isolation Kit (Ambion Inc, Foster City, CA) according to the manufacturer's instructions for total RNA isolation. The concentration of total RNA was quantified using a NanoDrop 1000 spectrophotometer (Thermo 217 Scientific, Waltham, MA). RNA integrity was assessed by agarose gel electrophoresis. First-strand complementary DNA (cDNA) was synthesized using the SuperScript III First-Strand Synthesis System (Invitrogen, Carlsbad, CA), according to the manufacturer's instructions with oligo(dT)20 and 600 ng of RNA. 
To determine cyclooxygenase II (COX II), 5-lipoxygenase (5-LOX), superoxide dismutase (SOD), catalase (CAT), and glutathione-peroxidase (GSHPx) gene expression, cDNA were amplified in quadruplicate by RT-qPCR using an ABI 7500 Real-Time PCR System (Applied Biosystem) in a $5 \mu$ reaction volume using $2.5 \mu 1$ 2X SYBR Green PCR Master Mix (Applied Biosystems, Carlsbad, CA) with $100 \mathrm{nM}$ of each primer and $1 \mu \mathrm{L}$ of diluted 1:10 cDNA sample.

The primer sequence for rat COX-II (Ptgs2, NM_017232) was (forward 5' CGGAGGAGAAGTGGGTTTTAG 3', and reverse 5' TGAAAGAGGCAAAGGGACAC 3'), 5-LOX was (forward 5' - CCA TCA AGA GCA GGG AGA AA - 3', reverse 5' - CAT AGT TGG AGG AGC GTT GG - 3'), Zinc/Copper (Zn/Cu SOD) SOD 1 was (forward 5' - GGT CCA CGA GAA ACA AGA TGA - 3', reverse 5' - CAA TCA CAC CAC AAG CCA AG 3'), CAT was (forward 5' - TGT TGA ATG AGG AGG AGA GGA - 3', reverse 5' - TTC TTA GGC TTC TGG GAG TTG - 3'), and GSH-Px was (forward 5' GAT ACG CCG AGT GTG GTT T - 3', reverse 5' - TCT TGA TTA CTT CCT GGC TCC T - 3'). The housekeeping gene GAPDH was used as an internal reference (forward 5' - TCA AGA AGG TGG TGA AGC AG - 3', reverse: 5' CCT CAG TGT AGC CCA GGA TG - 3’).

The program used for qRT-PCR amplification consisted of an initial temperature at $50^{\circ} \mathrm{C}$ for $2 \mathrm{~min}$ followed by an initial denaturation for $10 \mathrm{~min}$ at $95^{\circ} \mathrm{C}$ and $40 \mathrm{PCR}$ cycles. Each cycle comprised a melting step at $95^{\circ} \mathrm{C}$ for $15 \mathrm{sec}$ followed by a joint annealing/extension step at $60^{\circ} \mathrm{C}$ for $1 \mathrm{~min}$. Specificity of 
amplification was assessed by a melting curve of each amplicon, and visualization of the expected fragment size on $3 \%$ agarose gel. Data were expressed as relative gene expression to the control after normalization to the GAPDH housekeeping gene. Relative Expression Software Tool (REST) 2009 (Corbett Research Pty Ltd and Pfaffl, 2009) was used for gene expression calculation.

\subsection{Measurement of Eicosanoids}

Since $\mathrm{TXB}_{2}$ and $\mathrm{PGE}_{2}$ derived from ARA are a short-lived molecule, the stable metabolites 11-dehydro $\mathrm{TXB}_{2}$ and 13,14-dihydro-15-keto $\mathrm{PGE}_{2}$, respectively, were measured.

Pooled $7 \mathrm{~d}$ urine samples were collected during the final week of the $8 \mathrm{wk}$ feeding study. Rats were individually housed in metabolic cages to collect urine. Ascorbic acid $(0.1 \%)$ was added to the urine collection tubes as a preservative, and mineral oil $(1 \mathrm{~mL})$ was added to prevent evaporation. Pooled $7 \mathrm{~d}$ urine samples were centrifuged at $1,500 \mathrm{~g}$ for $10 \mathrm{~min}$ at $4^{\circ} \mathrm{C}$. Following centrifugation, urine samples were aliquoted into clean tubes.

Urinary 11-dehydro $\mathrm{TXB}_{2}$ and 13,14-dihydro-15-keto $\mathrm{PGE}_{2}$ were determined using a commercially available enzyme immunoassay kit according to the manufacturer's instructions (Cayman Chemical, Ann Arbor, MI). Absorbance was determined at wavelength $405 \mathrm{~nm}$ using a Spectramax Plus microplate reader (Molecular Devices, Sunnyvale, CA). All samples were performed in duplicates.

\subsection{Measurement of Oxidative Stability}

To determine lipid peroxidation, Thiobarbituric Acid Reactive Substances (TBARS) were measured in serum using a commercially available EIA kit 
(Cayman Chemical, MI). To determine TBARS, samples were mixed with sodium dodecyl sulfate (SDS) solution and a color reagent consisting of acetic acid, sodium hydroxide, and thiobarbituric acid (TBA). Samples incubated for $1 \mathrm{~h}$ in a $90^{\circ} \mathrm{C}$ water bath, and then were placed in an ice bath for 10 min to stop the reaction. Following centrifugation for $10 \mathrm{~min}$ at $1,600 \mathrm{xg}$ at $4^{\circ} \mathrm{C}$, absorbance was read at $540 \mathrm{~nm}$ using a Spectramax Plus microplate reader (Molecular Devices, CA). Samples were determined in duplicate. TBARS values were expressed as $\mu \mathrm{M} /$ malondialdehyde (MDA).

Total antioxidant capacity (TAC) was measured using a commercially available antioxidant assay colorimetric assay kit (Cayman Chemical, Ann Arbor, MI). Briefly, serum TAC was determined by diluting serum samples 1:20 v/v with $5 \mathrm{mM}$ potassium phosphate buffer ( $\mathrm{pH}$ 7.4) containing $0.9 \%$ sodium chloride and $0.1 \%$ glucose. Lung homogenates were prepared in $1 \mathrm{~mL}$ of $5 \mathrm{mM}$ potassium phosphate buffer ( $\mathrm{pH} 7.4)$. Absorbance was determined at $750 \mathrm{~nm}$ using a Spectramax Plus microplate reader (Molecular Devices, Sunnyvale, CA). All samples were determined in duplicate and values were expressed as nM Trolox equivalents.

\subsection{Statistical analyses}

Animal number was determined by performing a power analysis with power of 0.80 and $\alpha=0.05$. All results are expressed as mean \pm SEM. Data was analyzed by one-way analysis of variance (ANOVA) to determine the differences among the diet treatment groups. Post hoc multiple comparison tests were performed using Tukey's (parametric) or Kruskal-Wallis (non-parametric) test. 
Results with $p$-values of $<0.05$ are considered significant. All statistical analyses were performed using Sigma Stat (Abacus Concepts, Berkeley, CA). 


\section{RESULTS}

\subsection{Body and Lung Weights}

Over the 8 week study, rats showed no significant difference in final body weight, total body weight gain and total food intake (Table 3). The absolute lung weights of the rats fed SO were lower $(P=0.001)$ than rats fed $\mathrm{CO}, \mathrm{FO}, \mathrm{KO}$ or MO (Fig. 1A). Relative lung weights were lower $(P=0.001)$ in rats fed SO compared to rats fed $\mathrm{CO}, \mathrm{KO}$ or $\mathrm{MO}$ (Fig. 1B). Relative lung weights were also lower $(P=0.002)$ in rats fed TO compared to rats fed $\mathrm{CO}$.

\subsection{Lung Lipids and Fatty Acid Composition}

The lipid content of the lungs of rats fed $\mathrm{CO}$ was $3.4 \%$ lipid, 5.3\% for FO, $3.6 \%$ for $\mathrm{KO}, 4.9 \%$ for $\mathrm{MO}, 3.7 \%$ for $\mathrm{SO}$ and $3.8 \%$ for $\mathrm{TO}$. The percent of lipid in the lung of rats fed $\mathrm{FO}$ was significantly higher than rats fed $\mathrm{CO}, \mathrm{KO}, \mathrm{SO}$ or TO (Fig. 2). The percent lipid in rats fed MO was higher than rats fed $\mathrm{CO}, \mathrm{KO}$ or SO.

Table 4 shows the lung fatty acid composition of rats fed different sources of $\omega$-3 PUFAs. ALA was only detectable in the lungs of rats fed FO EPA was higher in the rats fed $\mathrm{KO}$ compared to all treatment diets, except for SO. Rats fed SO had higher $(P<0.001)$ lung EPA content than CO-fed rats. Lung DHA content was higher in rats fed TO compared to rats fed $\mathrm{CO}(P<0.001), \mathrm{FO}(P<0.001)$ or MO $(P=0.04)$. Lung DHA content was higher in the rats fed SO than rats fed CO $(P=0.001)$ or FO $(P=0.02)$. DHA content was also higher in the lungs of rats fed KO than rats fed $\mathrm{CO}(P<0.001)$ or FO $(P=0.006)$. 
Rats fed CO had the highest $(P<0.001)$ lung LA concentration among the treatment groups. FO had a significantly higher lung LA concentration than rats fed the fish oil diets MO $(P=0.01), \mathrm{SO}(P=0.004)$ or TO $(P=0.003)$. Rats fed CO had the highest lung AA concentrations $(P<0.001)$ among the treatment groups (Table 4).

The $\omega-6 / \omega-3$ ratio was 57:1 for rats fed CO, 2:1 for FO-fed rats, 1:1 for KO, MO, SO, and TO-fed rats (Table 4).

\subsection{Eicosanoid Metabolism}

The relative expression of 5-LOX was significantly up-regulated $(P=0.007)$ in rats fed FO compared to $\mathrm{CO}$-fed rats (Figure 3A). There were no treatment differences in the expression of COX II (Figure 3B).

No significant differences $(P<0.05)$ were observed in the concentration of urinary $\mathrm{TXB}_{2}$ (Figure 4A) or $\mathrm{PGE}_{2}$ metabolites (Figure 4B) among the dietary treatment groups.

\subsection{Oxidative Stability}

Serum TBARS were lower $(P<0.001)$ in rats fed SO or TO compared to rats fed $\mathrm{CO}, \mathrm{KO}$ or MO (Table 4). There were no significant differences in serum or lung tissue antioxidant capacity among the dietary treatment groups.

Expression of the antioxidant defense enzyme, superoxide dismutase was significantly down-regulated $(P=0.01)$ in TO-fed rats compared to rats fed $\mathrm{CO}$ (Figure 5C). There were no treatment differences in the expression of CAT (Figure 5A) or GSH-Px (Figure 5B). 


\section{DISCUSSION}

The lung is an organ that is constantly exposed to inflammation and oxidative stress due to its vast surface area (Schwartz, 2000). Most studies have used disease animal models or an exogenous trigger such as the bacterial endotoxin, lipopolysaccharide, to activate immune responses in the lungs (Calder, 2003). There have been few studies using healthy rodents as models for detecting the effects of diet on tissue $\omega$-3 PUFA content, specifically in the lungs. In addition, most studies in healthy animals use neonates. Yet, the prevalence of respiratory diseases among adults is increasing (Christie et al., 1999). Suarez et al. (1996) found that weanling rats fed $\omega-3$ PUFAs resulted in incorporation of $\omega$-3 PUFAs into the lungs. This has important implications because the ability of $\omega$-3 PUFAs to modulate lung fatty acid composition and eicosanoid activity may ameliorate the normal decline in lung function associated with age and may be protective against risk of lung damage and disease.

In our study, rats fed different sources of $\omega$-3 PUFAs had different lung weights. Rats fed SO or TO had lower $(P<0.01)$ relative lung weights compared to rats fed CO. Pankhania and Bakhle (1985) found increased lung weights in rats treated with a single dose of $\alpha$-naphthylthiourea, a rodenticide. The increased lung weight was due to edema caused by an increased production of 2-series prostaglandins and thromboxanes from AA. Therefore, lower lung weights in rats fed $\mathrm{SO}$ and $\mathrm{TO}$ may be protective since diets rich in $\omega-3$ PUFAs can competitively inhibit synthesis of pro-inflammatory 2-series eicosanoids (i.e. PGs and TXs) derived from AA.

In our study, a high fat diet ( $27 \%$ by kcals) was used to reflect the higher total fat intake typical of the Western diet ( $\sim 33 \%$ by kcals). The present study showed that the 
FA composition of the lungs reflected dietary intake in growing healthy rats fed a high fat diet. Rats fed FO, which has the highest dietary ALA content, had the highest lung ALA deposition. Rats fed KO, which has the highest dietary EPA content, had the highest lung EPA deposition compared to all diet groups, except rats fed SO. SO may be an exception because it had the highest dietary EPA to DHA ratio $(3: 1)$ of the $\omega$-3 PUFA sources. Lung DHA deposition was higher in rats fed TO, which has the highest dietary DHA content, compared to rats fed CO, FO or MO. Dietary DHA was not detectable in CO and FO. Of the marine oil sources, MO had the lowest dietary DHA content.

De novo synthesis of $\omega-3$ LC-PUFAs has been reported to occur in the liver, mammary gland, and adipose tissue (Ratnayake et al., 2009). De novo synthesis of the $\omega$ 3 LC-PUFAs, EPA and DHA, in the lungs was indicated by their presence in CO and FOfed rats. Rats fed CO and FO containing dietary ALA, but no dietary EPA or DHA, resulted in EPA and DHA deposition in the lungs. However, pre-formed EPA and DHA in marine sources resulted in significantly higher lung $\omega-3$ PUFA content than de novo synthesis in CO and FO-fed rats. Palombo et al. (1994) reported that continuous enteral feedings enriched with fish oil significantly increased the $\omega-3$ PUFA concentration of rat lung parenchymal tissue, macrophage and surfactant phospholipids in rats.

Efficient conversion of LA to $\omega-6$ LC-PUFAs in lung tissue was indicated by rats fed $\mathrm{CO}$ containing no detectable dietary AA having significantly higher AA deposition compared to rats fed FO, KO, MO, SO and TO. Rats fed FO, KO, MO and SO containing no detectable dietary AA also resulted in tissue AA, but lower $(P<0.001)$ amounts than rats fed CO. This may be due to more LA substrate available for conversion to AA in CO-red rats. 
Feeding FO or marine oils increased $\omega-3$ PUFAs resulting in a reduced $\omega-6$ to $\omega-3$ ratio. The $\omega-6$ PUFA to $\omega-3$ PUFA ratio was 57:1 for rats fed CO, 2:1 for FO-fed rats, 1:1 for KO-fed rats, 1:1 for MO-fed rats, 1:1 for SO-fed rats and 1:1 for TO-fed rats. A serum $\omega-6$ to $\omega-3$ ratio of 4:1 is suggested for optimal health (Simopoulos, 2008), however recommended tissue $\omega-6$ to $\omega-3$ ratios are unknown.

The observed decreases in the $\omega-6$ to $\omega-3$ ratios are significant because the FA composition of the lungs may influence a cascade of cellular responses. Increasing $\omega-3$ PUFAs, ALA and EPA results in a decreased production of pro-inflammatory eicosanoids, derived from $\omega$-6 PUFAs, by competing with LA and AA (Calder, 2003; Schwartz, 2000). In our study, lung AA was significantly decreased in rats fed FO and marine oils in comparison to $\mathrm{f}$ rats fed $\mathrm{CO}$. There was no significant difference in lung AA content in rats fed FO compared to the marine oils.

The lung manifests significant COX II and 5-LOX activity with their eicosanoid products playing an important role in pulmonary function (Meydani et al., 1992). AAderived eicosanoids such as $\mathrm{TXA}_{2}$ promotes bronchoconstriction and $\mathrm{PGE}_{2}$ and $\mathrm{LTB}_{4}$ are produced by mast cells that mediate pulmonary inflammation (Calder, 2003). Meydani et al. (1992) found that healthy mice, 3 or 24 months of age, fed marine oils had lower synthesis of $\mathrm{TXB}_{2}$ and $\mathrm{PGI}_{2}$. Therefore, synthesis of lung eicosanoids can contribute to pathological changes occurring in the respiratory system during the normal aging process. In our study, there were no significant differences $(P<0.05)$ observed in the concentration of urinary $\mathrm{TXB}_{2}$ or $\mathrm{PGE}_{2}$ among the dietary treatment groups. Due to the numerous eicosanoids and the difficulty of measuring these short-lived molecules, we also determined gene expression of COX II and 5-LOX. 
The FA composition of the lungs may influence the expression of various genes. Patterns in gene expression can reveal genetic predisposition and physiological condition. To our knowledge, there have been few feeding studies investigating the effect of $\omega-3$ PUFAs on inflammatory gene expression in the lungs. Most of these studies have used diseased mammalian models with the objective not on prevention, but on resolution. Results have reported that feeding patients $\omega$-3 PUFAs decreased their amount of complications and infections, as well as decreased severity, progression and length of hospital stay (Calder, 2003).

In our study, $\omega-3$ PUFAs as FO had effects in the lung. The expression of 5-LOX was significantly up-regulated $(P=0.007)$ in rats fed FO compared to $\mathrm{CO}$-fed rats. Of the dietary treatments, FO has the highest ALA content and resulted in significantly higher ALA deposition in the lungs. Due to the high ALA content, increased expression of 5LOX would result in the production of 5-series leukotrienes that are less biologically potent than the 3-series leukotrienes (Calder, 2003). Craig-Schmidt et al. (1987) found a decreased production of $\mathrm{PGE}_{2}$ and $\mathrm{TXB}_{2}$ when dietary ALA supplied as flaxseed oil was added to the diets of chickens.

Increasing tissue $\omega$-3 PUFA exerts beneficial physiological effects by influencing cell membrane fluidity, membrane-bound receptors, signaling molecules, and gene expression (Deckelbaum et al., 2006). However, higher tissue unsaturation needs to be considered since a greater number of double bonds may increase tissue susceptibility to lipid peroxidation. Therefore, DHA is particularly susceptible to lipid peroxidation due to its high degree of unsaturation (Song et al., 2011). The effect of $\omega$-3 PUFA intake on lipid peroxidation has produced inconsistent results of increased oxidation in the liver and 
kidney (Song et al., 2000; Song and Miyazawa, 2001; Yuan and Kitts, 2003), no effect on oxidation in plasma and red blood cell membranes (Calviello, 1997) and even decreased oxidation in mice livers (Demoz et al., 1992).

Our study showed rats fed TO, the highest dietary source of DHA or SO with the high DHA digestibility of the fish oils (Tou et al., 2011) resulted in lower $(P<0.001)$ serum TBARS compared to all diet groups, except FO-fed rats. Oxidative stress occurs when accumulation of oxidative products overwhelms the body's antioxidant capacity. TAC measures endogenous antioxidant, dietary antioxidant and interactions between antioxidants (Young, 2001). In our study, serum and lung homogenate TAC was not significantly different among the diet groups. Expression of the antioxidant defense enzyme, superoxide dismutase was down-regulated $(P=0.01)$ in TO-fed rats compared to rats fed CO. Probably due to less TBARS in TO-fed rats, there was no detectable expression or up-regulation of the level of antioxidants. Antioxidants such as alphatocopherol are routinely added to marine oils due to their high EPA and DHA, but not FO.

Dietary TO has an EPA/DHA ratio of $1: 2$ and had a higher $(P<0.001)$ lung DHA content compared to rats fed CO. DHA is more readily oxidized than ALA, LA and AA due to the presence of six double bonds (Song et al., 2000). SOD1 is an enzyme located in the cytosol that catalyzes the breakdown of superoxide into oxygen and hydrogen peroxide (McKee and McKee, 2009. Thus, they are an important antioxidant defense in nearly all cells exposed to oxygen. KO showed no differences in antioxidant gene expression despite suggestion of increased oxidative stability due to it being in the phospholipid form (Song et al., 2000). 


\section{SUMMARY AND CONCLUSION}

The present study evaluated the affect of popular sources of $\omega-3$ PUFAs on lung fatty acid composition and gene expression. The high fat diet ( $27 \%)$ by kcals) was used to reflect the higher total fat intake typical of the Western diet ( 33\% by kcals). Our study showed that the FA composition of the lungs reflected dietary intake in growing healthy rats fed high fat (12\% by weight) diets.

In our study, there were no significant differences observed in the concentration of serum TXB2 or urine PGE2 among the dietary treatment groups. Due to the numerous eicosanoids and the difficulty of measuring these short-lived molecules, we also determined gene expression of COX II and 5-LOX. The relative expression of 5-LOX was significantly up-regulated $(\mathrm{P}=0.007)$ in rats fed $\mathrm{FO}$ compared to $\mathrm{CO}$-fed rats.

Decreased serum TBARS in SO and TO-fed rats showed that these diets were protective against oxidative stress. Due to less TBARS in TO-fed rats, there was no detectable expression or up-regulation of the antioxidants. This is especially important in the lungs because of their increased susceptibility to oxidation compared to other organs.

These results are significant because the increase in $\omega-3$ PUFAs in lung tissue may affect the risk of lung damage, and in turn, susceptibility to lung diseases by altering gene expression of inflammation and oxidative stability. Few studies have reported on healthy non-neonate animals. Our study is novel because we saw changes in healthy animals that were past weaning age. Considering efficient tissue incorporation with the least amount of tissue lipid peroxidation, $\mathrm{FO}, \mathrm{SO}$ and $\mathrm{TO}$ appear to be the best sources of $\omega-3$ PUFAs most favorable to lung health. 


\section{FUTURE RESEARCH}

The goal of future research is to determine novel interventions that have the ability to prevent or modify the course of lung disease that is increasing in prevalence among infants and adults (Christie et al., 1999). Further research into dietary consumption of $\omega-3$ PUFAs for the prevention of lung inflammation and disease is a promising area of contribution.

Our study would benefit from looking at more measurements indicative of inflammation in the lung. An example of this would be the 5-LOX-derived eicosanoid, leukotriene at the tissue level versus systemic level. However, it is difficult to test hormones due to their short-lived nature, and only a limited number of laboratories have the developed methods for performing these measurements.

Instead, gene expression of regulators of inflammation may be determined. The family of nuclear receptors, peroxisome proliferator-activated receptors (PPARs) is expressed in various types of cells that play important roles in inflammation and immunity. PPAR $\alpha$ is abundant in macrophages, monocytes and endothelial cells, and PPAR $\gamma$ is abundant in alveolar epithelial cells and the bronchial sub-mucosa (Simon et al., 2006). The transcription factor nuclear factor kappa B (NF-кB) is a critical regulator of innate immune responses, including the pro-inflammatory cytokines (Uddin and Levy, 2010). Cheng et al. (2007) indicated that inhibition of NF-кB activation in airway epithelium reduces lung inflammation and injury induced by the gram-negative bacteria lipopolysaccharide. Measuring NF-кB in a healthy animal lung model has yet to be researched. 
Another exciting area of research in $\omega-3$ PUFAs and lung health are pro-resolving mediators. Resolvins are a novel class of mediators generated from EPA and DHA that act to promote resolution of inflammation (Uddin and Levy, 2010). The pulmonary inflammatory response can either progress to chronic lung inflammation or complete resolution. According to Uddin and Levy (2012), resolvins have the ability to restore lung homeostasis by acting in a cell-specific manner to reduce pulmonary inflammation and promote tissue catabasis. It would be interesting to investigate whether different dietary sources of $\omega-3$ PUFAs affect the concentration of resolvins in the lungs. 


\section{REFERENCES}

Anandan C, Nurmatov U, Sheikh A. Omega 3 and 6 oils for primary prevention of allergic disease: systematic review and meta-analysis. Allergy 2009; 64:840848.

Bayon Y, Croset M, Daveloose D, et al. Effect of specific phospholipid molecular species incorporated in human platelet membranes on thromboxane A2/prostaglandin $\mathrm{H}_{2}$ receptors. J. Lipid Res. 1995; 36:47-56.

Blok W, Katan M, van der Meer J. Modulation of inflammation and cytokine production by dietary ( $\omega-3)$ fatty acids. J. Nutr. 1996; 126:1515-1533.

Bonilla D, Fan Y, Chapkin R, et al. Transgenic Mice Enriched in $\omega$-3 Fatty Acids are more Susceptible to Pulmonary Tuberculosis: Impaired Resistance to Tuberculosis in fati-1 Mice. JID 2010; 201:399-408.

Calder, P. n-3 Polyunsaturated Fatty acids and Inflammation: From Molecular Biology to the Clinic. Lipids. 2003; 38:343-352.

Calviello G, Palozza P, Franceschelli P, Bartoli GM. Low-dose eicsapentaenoic or docosahexaenoic acid administration modifies fatty acid composition and does not affect susceptibility to oxidative stress in rat erythrocytes and tissues. Lipids 1997, 32:1075-1083.

Christie G, Helms P, Godden D, Ross S, Friend J, Legge J, et al. Asthma, wheezy bronchitis, and atopy across two generations. Am J Respir Crit Care Med. 1999; 159: $125-129$. 
Craig-Schmidt M, Faircloth S, Weete J. Modulation of avian lung eicosanoids by dietary omega-3 fatty acids. J. Nutr. 1987; 117:1197-1206.

Cunnane SC. Nutritional attributes of traditional flaxseed in healthy young adults. Am J Clin Nutr 1995, 61:62-68.

D'ambola J, Aeberhard E, Trand N, et al. Effect of dietary $\omega-3$ and $\omega-6$ fatty acids on in vivo pulmonary bacterial clearance by neonatal rabbits. J. Nutr. 1991; $121: 1262-1269$.

Day BJ. Antioxidants as potential therapeutics for lung fibrosis. Antioxid. Redox. Signal. 2008; 10(2):355-370.

Dehler M, Zessin E, Bartsch P and Mairba url H. Hypoxia causes permeability oedema in the constant-pressure perfused rat lung. Eur Respir J. 2006; 27: 600606.

Demoz A, Willumsen N, Berge RK: Eicosapentaenoic acid at hypotriglyceridemic dose enhances the hepatic antioxidant defense in mice. Lipids. 1992; 27: 968-971.

Ebert S, Kannenberg F, Somoza V. et al. Dietary alpha-linolenic acid, EPA, and DHA have differential effects on LDL fatty acid composition but similar effects on serum lipid profiles in normolipidemic humans. J. Nutr. 2009; 139:861-868.

Fritsche K, Johnston P. Effect of dietary alpha-linolenic acid on growth, metastasis, fatty acid profile and prostaglandin production of two murine mammary adenocarcinomas. J. Nutr. 1990; 120:1601-1609. 
Galli C, Calder P. Effects of fat and fatty acid intake on inflammatory and immune responses: A critical review. Ann. Nutr. Metab. 2009; 55:123-139.

Gigliotti JC, Davenport M, Beamer S, Tou JC and Jaczynski J. Extraction and characterization of lipids from Antarctic krill (Euphausia superba). Food Chemistry 2011; 125(3): 1028-1036.

Harding R, Pinkerton KE. Lung Anatomy (Including the Aging Lung). Am. J. of Anatomy. 1982; 164:155-174.

Hlastala MP and Berger AJ. Physiology of Respiration. Seattle, WA: Oxford University Press, 2001.

Hopkins DT, Witter RL, Nesheim MC. A respiratory disease syndrome in chickens fed essential fatty acid deficient diets. Proc. Soc. Exp. Biol. Med. 1963; 114:82-86.

Horrobin DF. Low prevalences of coronary heart disease (CHD), psoriasis, asthma and rheumatoid arthritis in Eskimos: are they caused by high dietary intake of eicosapentaenoic acid (EPA), a genetic variation of essential fatty acid (EFA) metabolism or a combination of both? Med Hypotheses 1987; 22(4):421428.

Ismail $\mathrm{H}$. The role of omega-3 fatty acids in cardiac protection: an overview. Frontiers in Bioscience 2005; 10:1079-1088. 
Kehrer JP, Autor AP. Changes in the fatty acid composition of rat lung lipids during development and following age-dependent lipid peroxidation. Lipids 1977; 12(7): 596-603.

Kinnery P, Amrani Y, Vachani A, et al. Dietary Flaxseed Supplementation ameliorates inflammation and oxidative tissue damage in experimental models of acute lung injury in mice. J. Nutr. 2006; 136:1545-1551.

Kinnula VL and Crapo JD. Superoxide Dismutases in the Lung and Human Lung Diseases. Am. J. Respir. Crit. Care Med. 2003; 167 (12): 1600-1619.

Lang J, McArdle P, O'Reilly P, et al. Oxidant-antioxidant balance in acute lung injury. Chest. 2002; 122: 314S-320S.

Matsuyama W, Mitsuyama H, Watanabe M, et al. Effects of Omega-3

Polyunsaturated Fatty Acids on Inflammatory Markers in COPD. Chest 2005; 128(6): 3817-3827.

Meydani SN, Shapiro MM, Blumberg JB. Lung Eicosanoid Synthesis is affected by Age, Dietary Fat and Vitamin E. J. Nutr. 1992; 122:1627-1633.

McKee T and McKee JR. Biochemistry: the molecular basis of life. New York, NY: Oxford University Press, 2009. Print.

Mihrshahi S, Peat JK, Webb K, Tovey ER, Marks GB, Mellis CM, Leeder SR. The childhood asthma prevention study (CAPS): design and research protocol of a randomized trial for the primary prevention of asthma. Control Clin Trials 2001 Jun; 22(3):333-54. 
National Research Council. "Front Matter." Guide for the Care and Use of Laboratory Animals. Washington, DC: The National Academies Press, 1996. 1. Print.

Nelms M, Sucher K, Long S. Nutrition Therapy and Pathophysiology. Belmont, CA: Thomson Brooks/Cole, 2007. Print.

O'Byrne P, Inman M. Airway Hyperresponsiveness. CHEST 2003; 123:411S416S.

Palombo J, Lydon E, Chen P., et al. Fatty acid composition of lung, macrophage and surfactant phospholipids after short-term enteral feeding with n-3 lipids. Lipids 1994; 29: 643-649.

Pankhania JJ and Bakhle YS. Effect of pulmonary oedema induced by $\alpha-$ naphthylthiourea on synthesis of cyclo-oxygenase products in rat isolated lungs. Prostaglandins. 1985; 30(1): 37-49.

Ratnayake WM, Galli C. Fat and fatty acid terminology, methods of analysis and fat digestion and metabolism: a background review paper. Ann Nutr Metab 2009, 55:8-43.

Reeves P, Nielsen F, Fahey G. AIN-93 Purified Diets for Laboratory Rodents: Final report of the American Institute of Nutrition Ad Hoc Writing Committee on the reformulation of the AIN-76A rodent diet. J Nutr 1993; 123: 1939-1951. 
"Report of the NIH Rat Model Priority Meeting."

http://www.nhlbi.nih.gov/meetings/. National Heart, Lung and Blood Institute, 3

May 1999. Web. 2 Apr. 2012.

Sherwood L, Klandorf H, Yancey PH. Animal Physiology: From Genes to

Organisms. Belmont, CA: Thomson Brooks/Cole, 2005. Print.

Schwartz J. Role of polyunsaturated fatty acids in lung disease. Am J Clin Nutr 2000; 71(suppl): 393S-6S.

Simon DM, Arikan MC, Srisuma S, et al. Epithelial cell PPAR $\gamma$ contributes to normal lung maturation. FASEB. 2006; 20: E710-E719.

Simopoulos A. The Importance of the Omega-6/Omega-3 Fatty Acid Ratio in Cardiovascular Disease and Other Chronic Diseases. Exp Biol Med 2008; 233:674-688.

Simopoulos A, Leaf A, Salem N, Jr. Essentiality of and recommended dietary intakes for omega-6 and omega-3 fatty acids. Ann Nutr Metab 1999; 43(2):127130.

Song JH, Fujimoto K, Miyazawa T. Polyunsaturated (n-3) fatty acids susceptible to peroxidation are increased in plasma and tissue lipids of rats fed docosahexaenoic acid-containing oils. J. Nutr. 2000; 130:3028-3033.

Song JH, Miyazawa T: Enhanced level of n-3 fatty acid in membrane phospholipids induces lipid peroxidation in rats fed dietary docosahexaenoic acid oil. Atherosclerosis 2001, 155:9-18. 
Spragg R and Lewis J. Pathology of the Surfactant System of the Mature Lung. Am. J. Respir. Crit Care Med. 2001; 163(1): 280-283.

Suarez A, Faus MJ, Gil A. Dietary long-chain polyunsaturated fatty acids modify heart, kidney, and lung fatty acid composition in weanling rats. Lipids 1996; 31 : 345-348.

"The Lungs in Health and Disease". http://www.nhlbi.nih.gov/health/public/lung/index.htm. National Heart Lung and Blood Institute, 1997. Web. 2 April 2012.

Tiesset H, Pierre M, Desseyn JL, et al. Dietary $\omega-3$ Polyunsaturated Fatty Acids Affect the Kinetics of Pro- and Anti-inflammatory Responses in Mice with Psuedomonas aeruginosa Lung Infection. J. Nutr. 2009; 139:82-89.

Tou JC, Altman SN, Gigliotti JC, Benedito VA, Cordonier EL. Different sources of omega-3 polyunsaturated fatty acids affects apparent digestibility, tissue deposition, and tissue oxidative stability in growing female rats. Lipids Health Dis. 201; 10:179.

Tou JC, Jaczynski J, Chen YC. Krill for human consumption: nutritional value and potential health benefits. Nutr Rev. 2007; 65: 63-77.

Uddin M and Levy BD. Resolvins: Natural agonists for resolution of pulmonary inflammation. Prog Lipid Res. 2011; 50:75-88. Epub 2010 Sep 29.

Wright JR. Pulmonary surfactant: a front line of lung host defense. J. Clin. Invest. 2003; 111: 1453-1455. 
Xu H, Watkins B, Adkisson H. Dietary lipids modify the fatty acid composition of cartilage, isolated chondrocytes and matrix vesicles. Lipids 1994; 29: 619-625.

Yang X, Dick T. Dietary alpha-linolenic and linoleic acids competitively affect metabolism of polyunsaturated fatty acids in arctic charr (Salvelinus alpinus). J. Nutr. 1994; 124: 1133-1145.

Young IS. Measurement of total antioxidant capacity. J Clin Path 2001; 54:339.

Yuan YV, Kitts DD. Dietary (n-3) fat and cholesterol alter tissue antioxidant enzymes and susceptibility to oxidation in SHR and WKY rats. J. Nutr. 2003, 133:679-688. 
Table 1: Diet Composition

\begin{tabular}{|c|c|c|c|c|c|c|}
\hline${\text { Ingredients (g/Kg diet) }{ }^{1}}^{1}$ & $\mathrm{CO}^{2}$ & FO & KO & MO & SO & TO \\
\hline Casein & 200 & 200 & 200 & 200 & 200 & 200 \\
\hline L-Cystine & 3 & 3 & 3 & 3 & 3 & 3 \\
\hline Corn Starch & 347.5 & 347.5 & 347.5 & 347.5 & 347.5 & 347.5 \\
\hline Maltodextrin & 132 & 132 & 132 & 132 & 132 & 132 \\
\hline Sucrose & 100 & 100 & 100 & 100 & 100 & 100 \\
\hline Source (Marine/Plant) Oil & 0 & 120 & 118 & 118 & 120 & 120 \\
\hline Corn Oil & 120 & 0 & 2 & 2 & 0 & 0 \\
\hline Cellulose & 50 & 50 & 50 & 50 & 50 & 50 \\
\hline Mineral Mix, AIN-93G-MX & 35 & 35 & 35 & 35 & 35 & 35 \\
\hline Vitamin Mix, AIN-93-VX & 10 & 10 & 10 & 10 & 10 & 10 \\
\hline Choline Bitartrate & 2.5 & 2.5 & 2.5 & 2.5 & 2.5 & 2.5 \\
\hline
\end{tabular}

${ }^{\mathrm{T}}$ Based on the AIN-93G vitamin and mineral mixes (Reeves et al., 1993).

${ }^{2}$ Abbreviations are CO, corn oil; FO, flaxseed oil; KO, krill oil; MO, menhaden oil; SO, salmon oil; TO, tuna oil. 
Table 2: Fatty Acid Profile of Dietary Oils ${ }^{1}$

\begin{tabular}{|c|c|c|c|c|c|c|}
\hline & $\mathrm{CO}^{2}$ & FO & KO & MO & SO & TO \\
\hline \multicolumn{7}{|l|}{$\omega-6$ PUFAs } \\
\hline LA; $18: 2$ & 618.37 & 163.25 & 30.05 & 4.49 & 24.98 & 21.98 \\
\hline AA; $20: 4$ & 0 & 0 & 0 & 0 & 0 & 26.84 \\
\hline \multicolumn{7}{|l|}{$\omega-3$ PUFAs } \\
\hline ALA; $18: 3$ & 11.55 & 584.83 & 19.71 & 18.9 & 9.36 & 10.06 \\
\hline EPA; 20:5 & 0 & 0 & 323.62 & 60.65 & 99.39 & 117.98 \\
\hline DHA; 22:6 & 0 & 0 & 115.46 & 26.53 & 29.37 & 405.34 \\
\hline EPA:DHA & $\mathrm{n} / \mathrm{a}$ & $\mathrm{n} / \mathrm{a}$ & $3: 1$ & $3: 1$ & $3: 1$ & $1: 2$ \\
\hline$\omega-6: \omega-3$ & $73: 1$ & $1: 3$ & $1: 33$ & $1: 48$ & $1: 23$ & $1: 12$ \\
\hline
\end{tabular}

${ }^{1}$ Results are given as $\mathrm{mg} \mathrm{FA} / \mathrm{mL}$ lipid

${ }^{2}$ Abbreviations are CO, corn oil; FO, flaxseed oil; KO, krill oil; MO, menhaden oil; SO, salmon oil; TO, tuna oil; PUFAs, polyunsaturated fatty acids; LA, linoleic acid; AA, arachidonic acid; ALA, alpha-linolenic acid; EPA, eicosapentaenoic acid; DHA, docosahexaenoic acid 
Table 3: The Effect of Feeding Growing Female Rats Fed Different Sources of Omega-3 Polyunsaturated Fatty Acids on Body Weight, Weight Gain and Food Intake

\begin{tabular}{lllllll}
\hline Treatment & CO $^{2}$ & FO & KO & MO & SO & TO \\
\hline Final body weight $(\mathrm{g})$ & $214.9 \pm 20.1$ & $239.6 \pm 26.1$ & $231.7 \pm 20.8$ & $241.5 \pm 45.5$ & $215.5 \pm 32.5$ & $234.9 \pm 25.9$ \\
Total Weight Gain $(\mathrm{g})$ & $76.0 \pm 7.4$ & $103.8 \pm 8.1$ & $98.4 \pm 6.1$ & $107.6 \pm 12.5$ & $86.0 \pm 8.4$ & $106.0 \pm 6.7$ \\
Total Food Intake $(\mathrm{g})$ & $750.1 \pm 12.5$ & $762.9 \pm 14.3$ & $767.4 \pm 10.9$ & $761.2 \pm 17.6$ & $706.8 \pm 17.4$ & $738.3 \pm 16.4$ \\
\hline
\end{tabular}

${ }^{1}$ Values are the mean \pm SEM of $n=10$ rats/group

${ }^{2}$ Abbreviations are CO, corn oil; FO, flaxseed oil; KO, krill oil; MO, menhaden oil; SO, salmon oil; TO, tuna oil 


\section{Figure 1:}

A) Absolute lung weights (g) of growing female rats fed different sources of omega-3 polyunsaturated fatty acids.

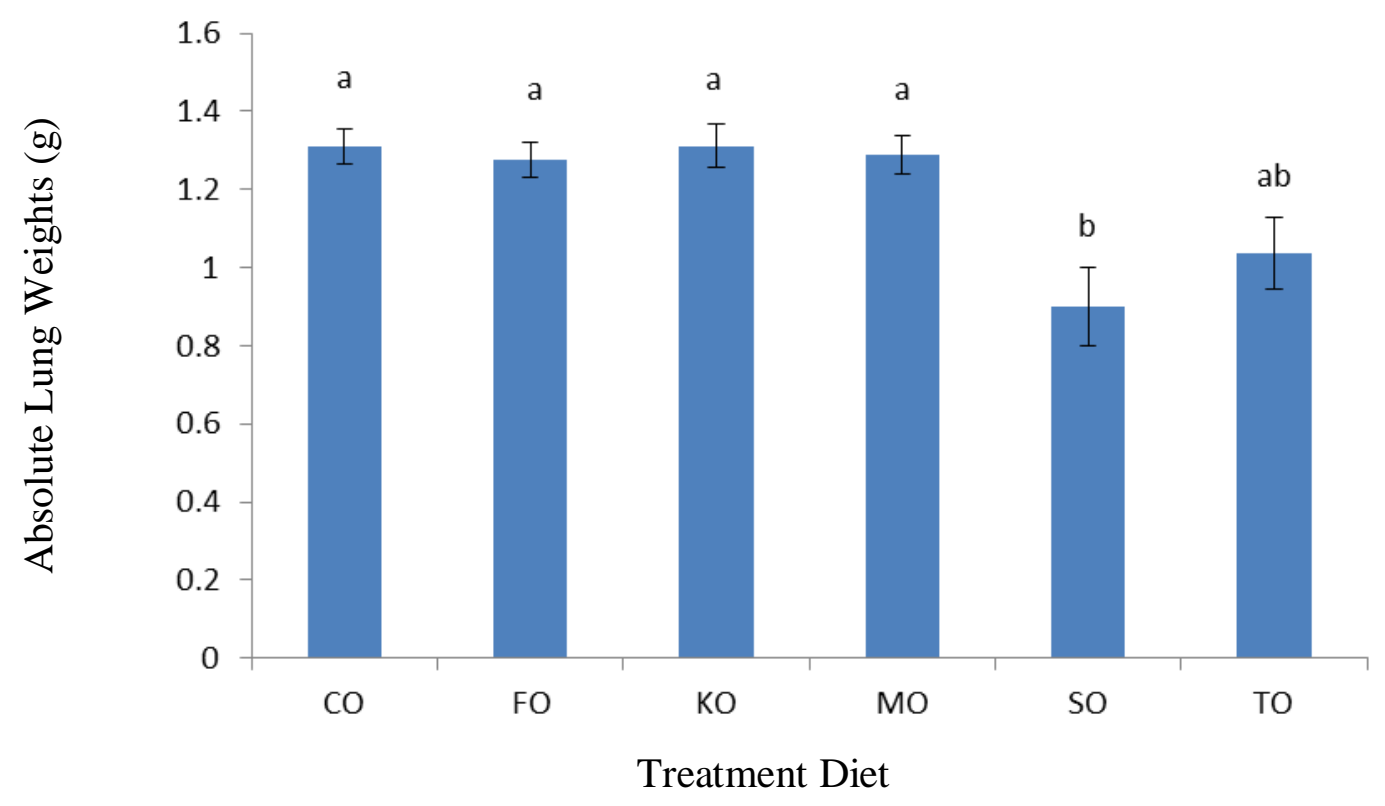

The different letters a, b, indicate significant differences at $P<0.05$ by one-way ANOVA followed by Tukey's test. Values are the mean $\pm S E M$ of $n=10$ rats/group. 
B) Relative lung weights (mg/100g bwt) of growing female rats fed different sources of omega-3 polyunsaturated fatty acids.

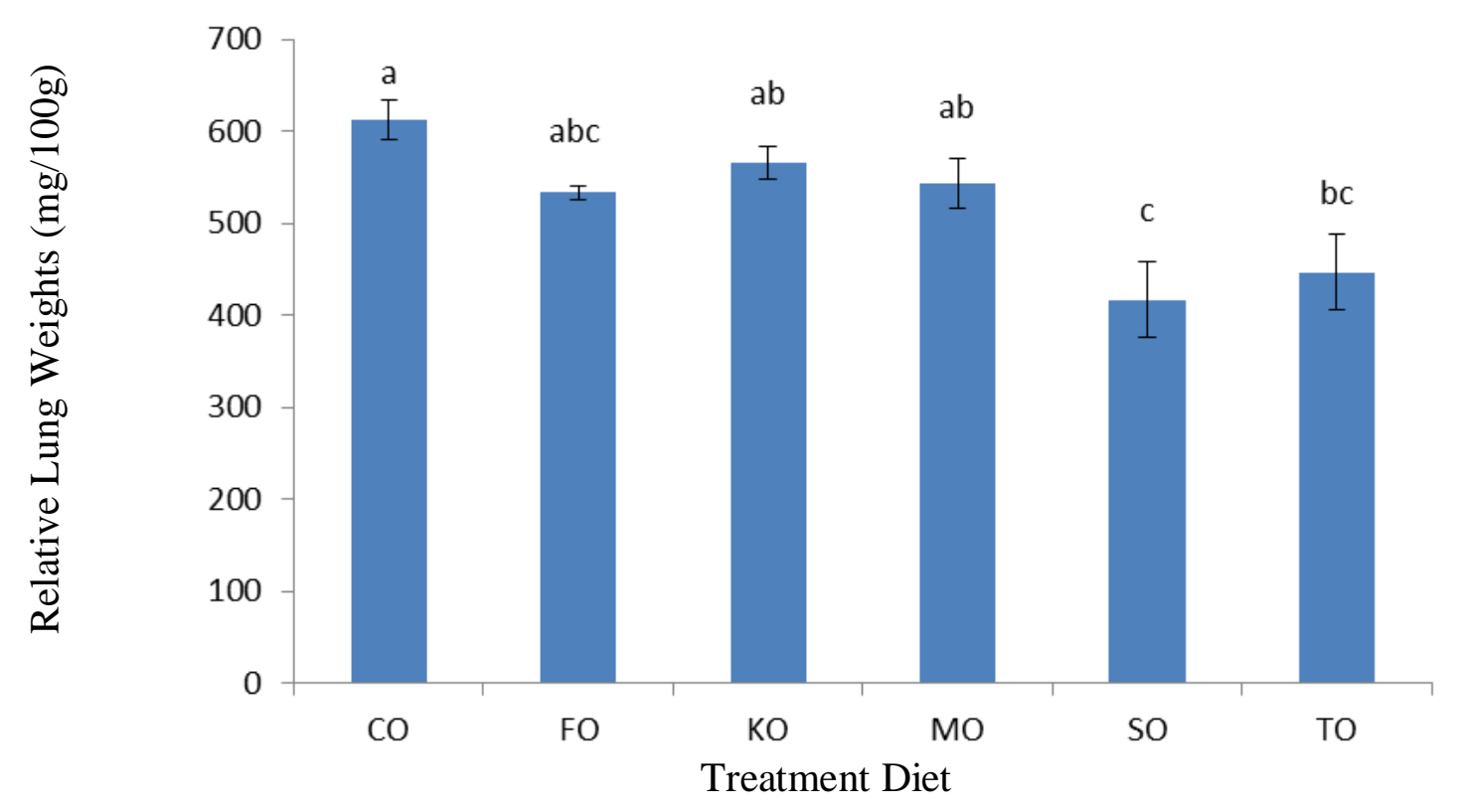

The different letters a, b, c indicate significant differences at $P<0.05$ by one-way ANOVA followed by Tukey's test. Values are the mean $\pm S E M$ of $n=10$ rats/group. 
Figure 2: Percent lipid in the lungs of growing female rats fed different sources of omega-3 polyunsaturated fatty acids. ${ }^{1}$

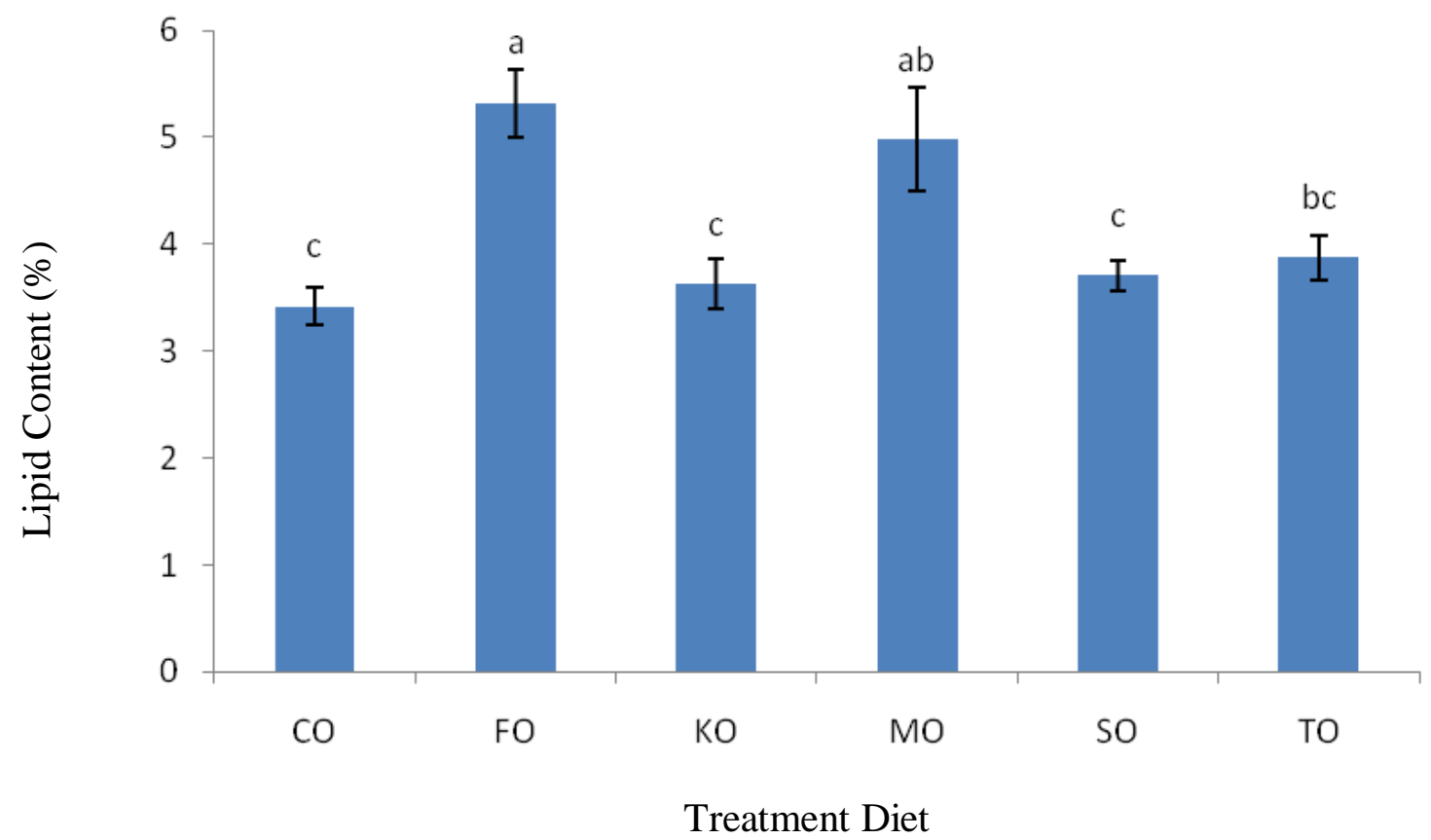

${ }^{1}$ The different letters a, b, c indicate significant differences at $P<0.05$ by one-way ANOVA followed by Tukey's test. Values are the mean \pm SEM of $n=10$ rats/group 
Table 4. Fatty acid composition in the lungs of growing female rats fed different sources of omega-3 polyunsaturated fatty acids. ${ }^{1}$

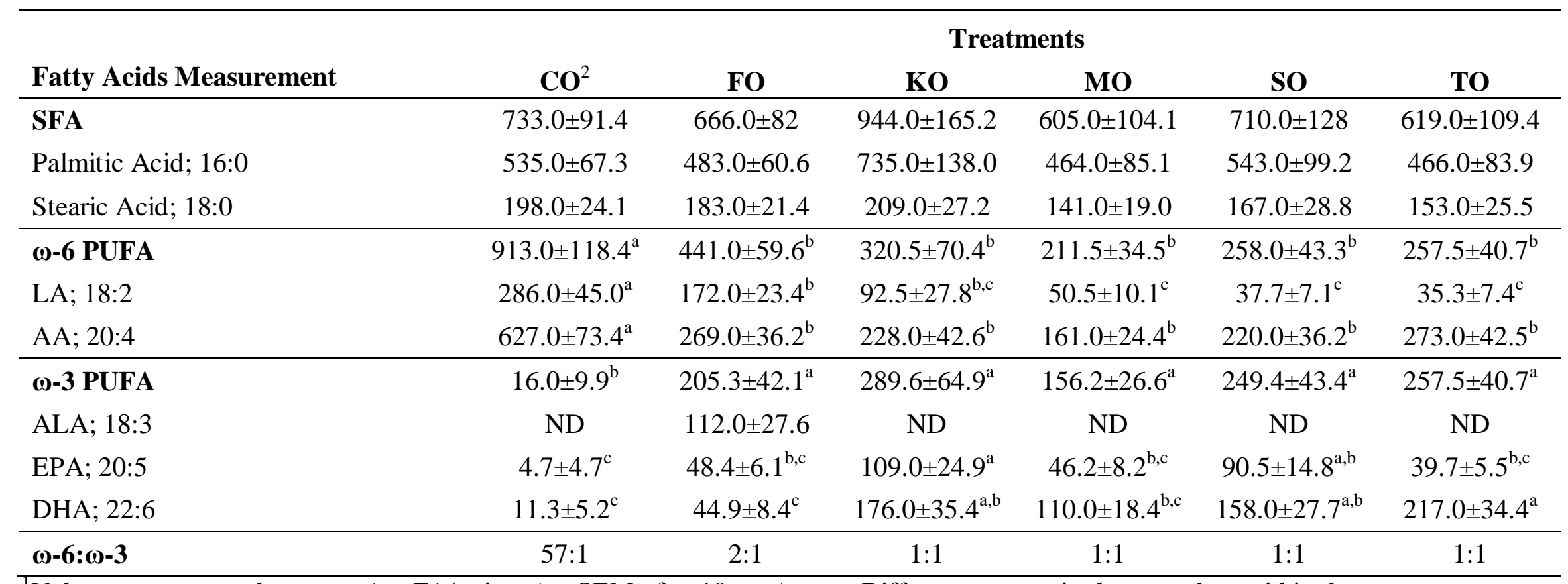

${ }^{\mathrm{T}}$ Values are expressed as mean ( $\mu \mathrm{g}$ FA/g tissue) \pm SEM of $\mathrm{n}=10$ rats/group. Different superscript letters a, b, $\mathrm{c}$ within the same rows indicate significant differences at $P<0.05$ by one-way ANOVA followed by Tukey's test (parametric) or Kruskal-Wallis test (non-parametric).

${ }^{2}$ Abbreviations are: CO, corn oil; FO, flaxseed oil; KO, krill oil; MO, menhaden oil; SO, salmon oil; TO, tuna oil.; SFA, saturated fatty acids; PUFA, polyunsaturated fatty acids; ND, not detectable; LA, linoleic acid; AA, arachidonic acid; ALA, alpha-linolenic acid; EPA, eicosapentaenoic acid; DHA, docosahexaenoic acid. 


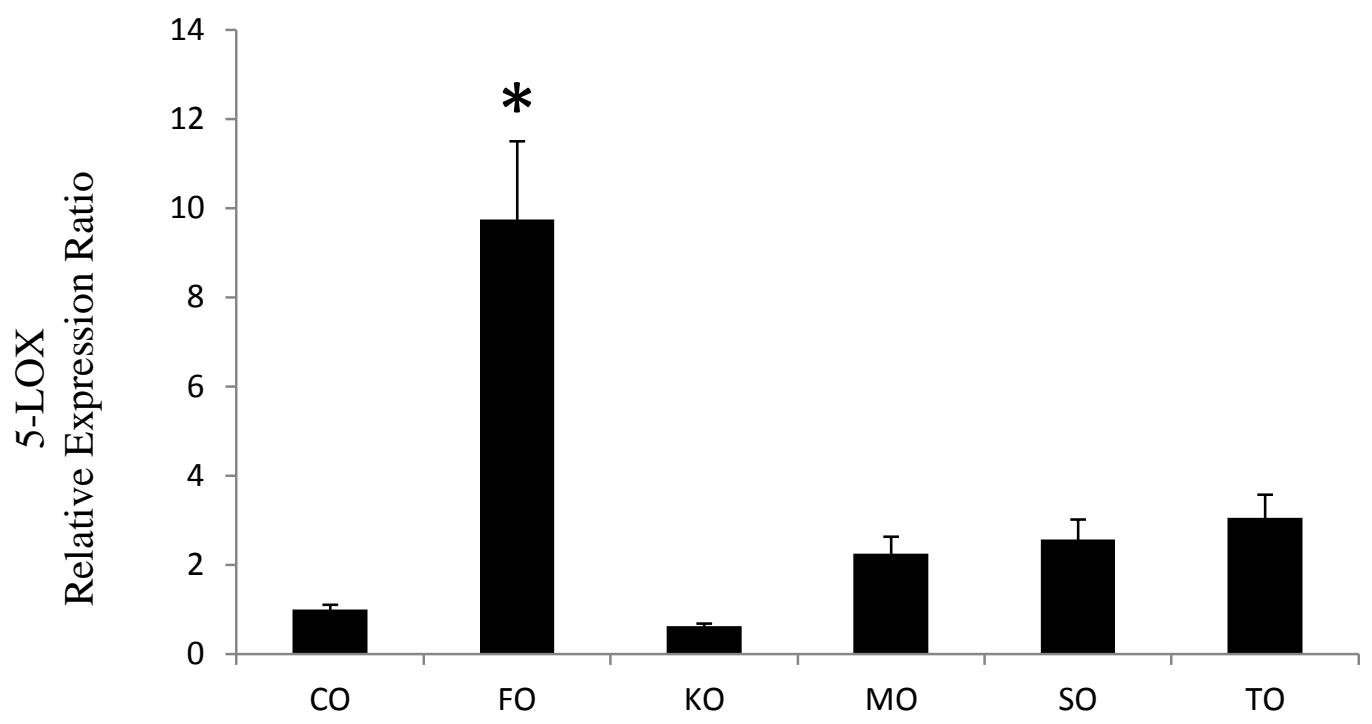

Treatment Diet

B)

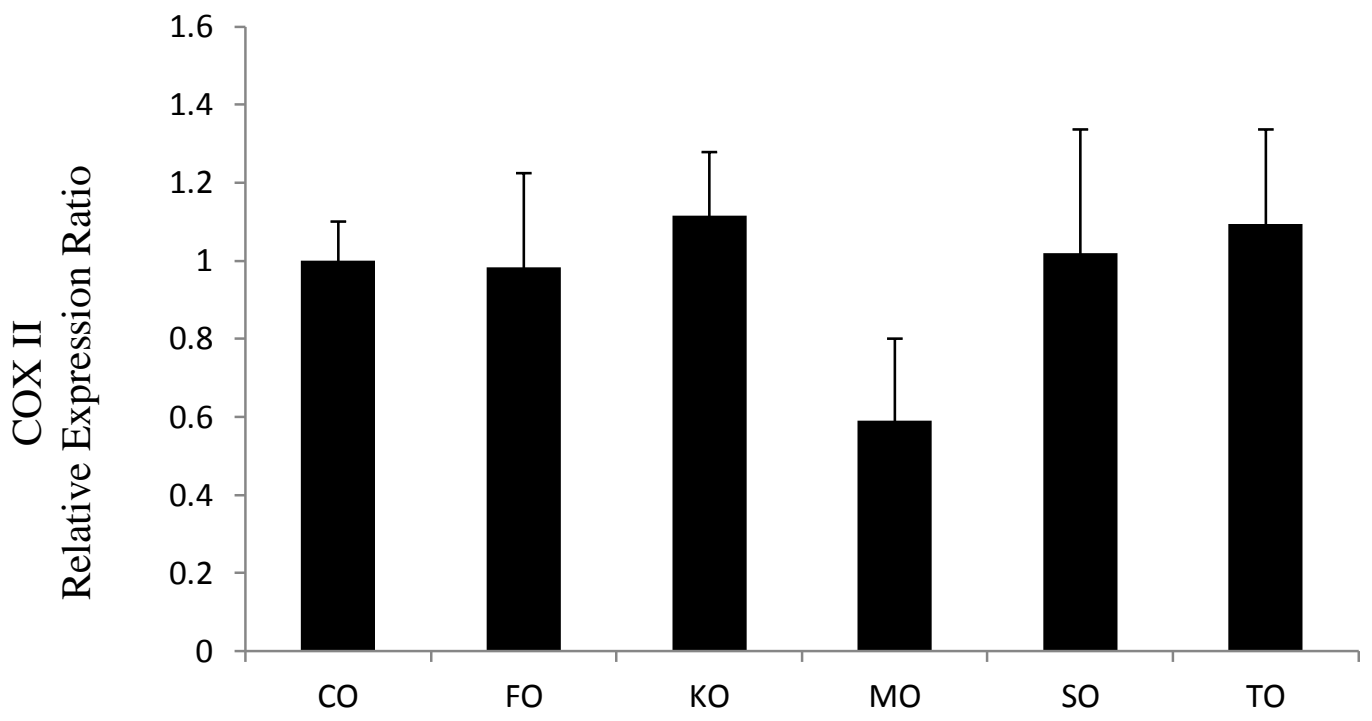

Treatment Diet

Figure 3. The effect of feeding growing female rats fed different sources of omega-3 polyunsaturated fatty acids on gene expression of A) 5-lipoxygenase (5-LOX) and B) cyclooxygenase II (COX II). Values are relative mRNA expression to corn oil treatment (control) after normalization to the GAPDH housekeeping gene expressed as ratios. Abbreviations are: $\mathrm{CO}$, corn oil; FO, flaxseed oil; KO, krill oil; MO, menhaden oil; SO, salmon oil; TO, tuna oil. 


\section{Figure 4:}

A) Urine $\mathrm{TXB}_{2}$ Metabolite Concentrations (pg/mL) in Young Growing Rats Fed Different Sources of Omega-3 Polyunsaturated Fatty Acids.

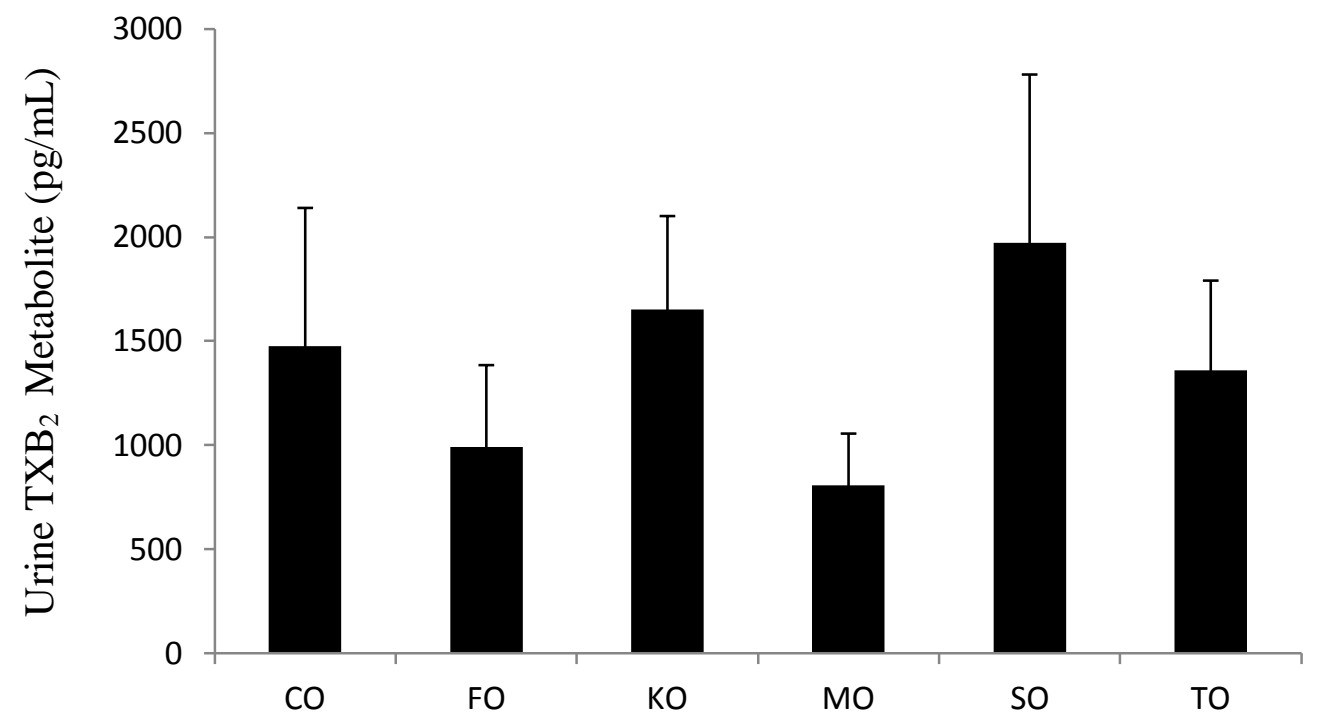

Treatment Diet

B) Urine $\mathrm{PGE}_{2}$ Metabolite Concentrations (ug/d) in Young Growing Rats Fed Different Sources of Omega-3 Polyunsaturated Fatty Acids.

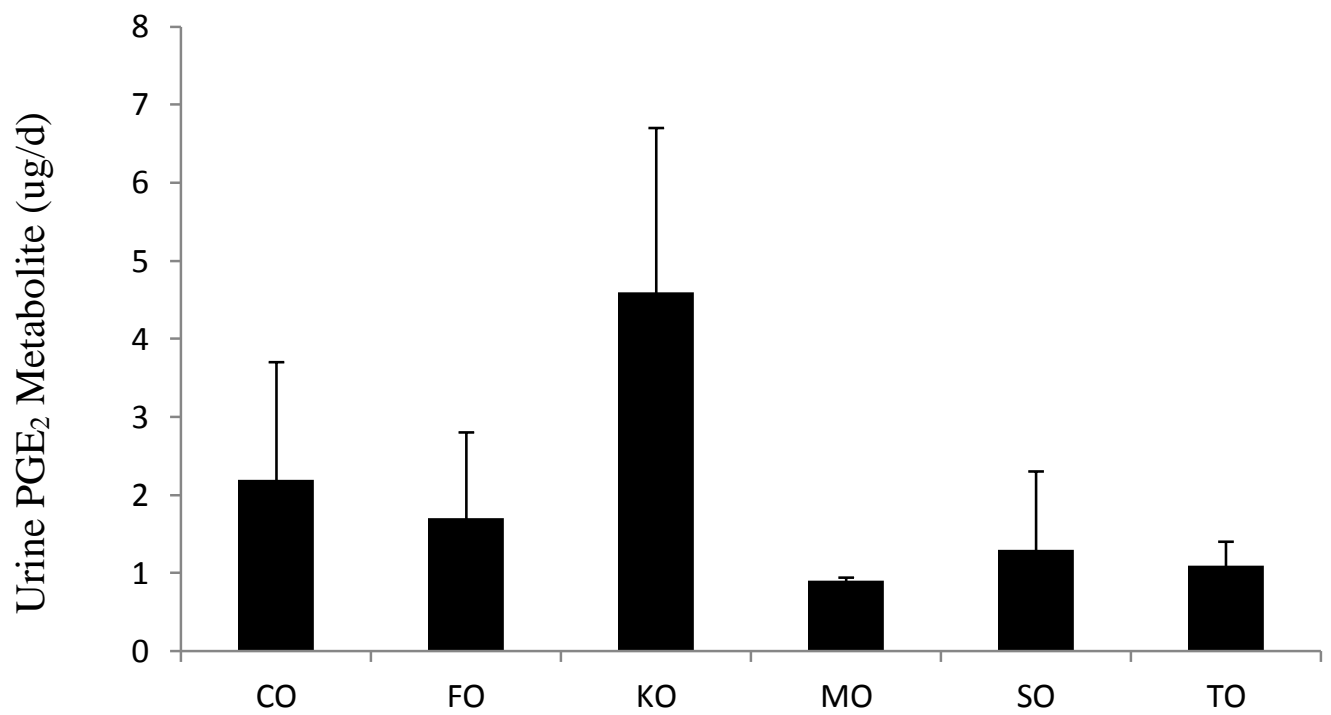

Treatment Diet 
A)

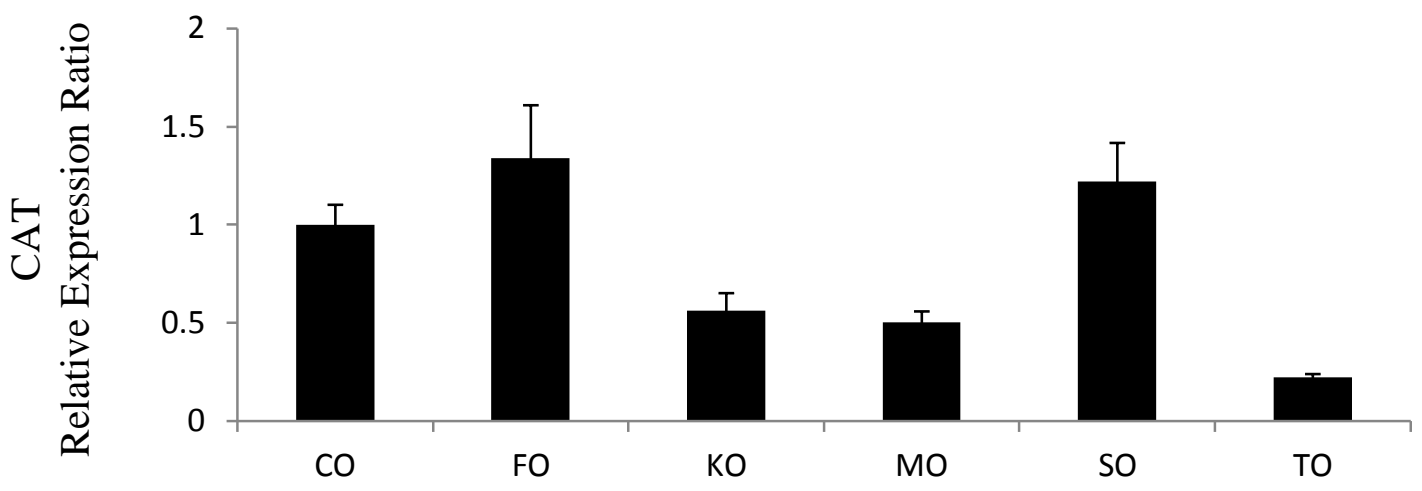

Treatment Diet

B)

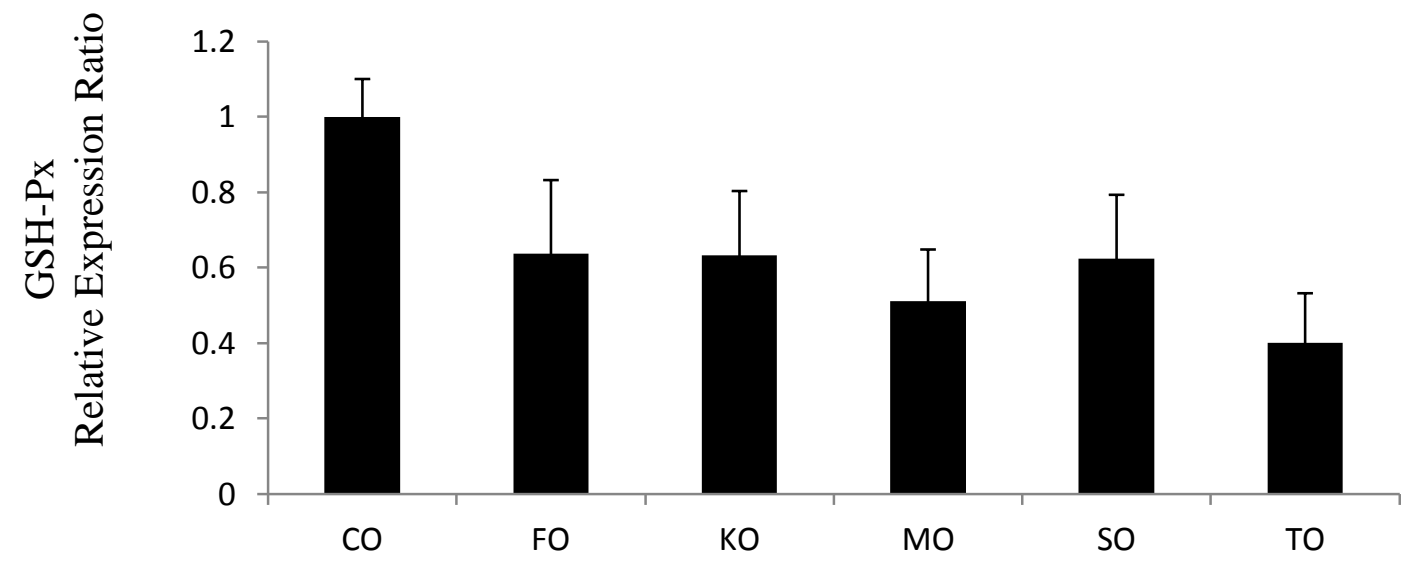

Treatment Diet

C)

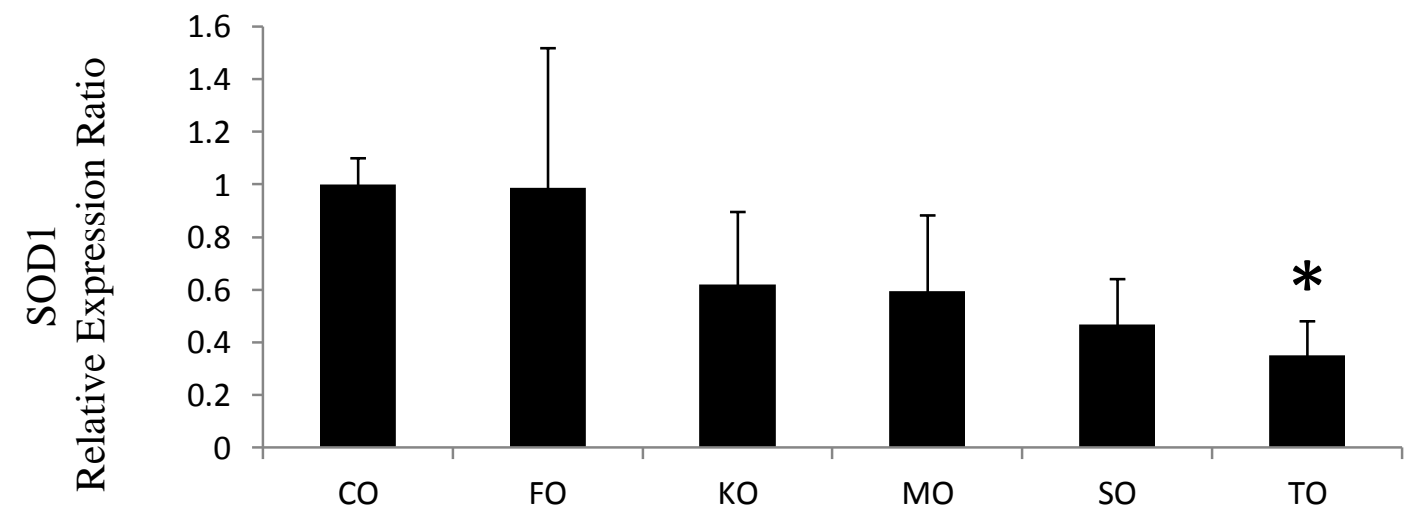




\section{Treatment Diet}

Figure 5. The effect of feeding growing female rats fed different sources of omega-3 polyunsaturated fatty acids on gene expression of A) catalase (CAT), B) glutathione-peroxidase (GSH-Px) and C) superoxide dismutase 1 (SOD1). Values are relative mRNA expression to corn oil treatment (control) after normalization to the GAPDH housekeeping gene expressed as ratios. Abbreviations are: $\mathrm{CO}$, corn oil; FO, flaxseed oil; KO, krill oil; MO, menhaden oil; SO, salmon oil; TO, tuna oil. 
Table 5: Oxidative Stability Measurements in Young Growing Rats Fed Different Sources of Omega-3 Polyunsaturated Fatty Acids

\begin{tabular}{|c|c|c|c|c|c|c|}
\hline Treatments & $\mathrm{CO}^{1}$ & FO & KO & MO & SO & TO \\
\hline Serum TBARS $(\mu \mathrm{M}$ MDA) & $6.9 \pm 0.4^{\mathrm{a}}$ & $5.9 \pm 0.2^{\mathrm{ab}}$ & $6.5 \pm 0.3^{\mathrm{a}}$ & $6.8 \pm 0.3^{\mathrm{a}}$ & $5.1 \pm 0.3^{b}$ & $5.2 \pm 0.2^{b}$ \\
\hline $\begin{array}{l}\text { Serum Antioxidant Capacity } \\
\text { (mM Trolox) }\end{array}$ & $1.5 \pm 0.2$ & $1.1 \pm 0.1$ & $1.3 \pm 0.1$ & $1.5 \pm 0.2$ & $1.1 \pm 0.2$ & $1.2 \pm 0.2$ \\
\hline $\begin{array}{l}\text { Lung Antioxidant Capacity } \\
\text { (mM Trolox/g Tissue) }\end{array}$ & $0.1 \pm 0.05$ & $0.08 \pm 0.05$ & $0.08 \pm 0.02$ & $0.1 \pm 0.04$ & $0.1 \pm 0.04$ & $0.1 \pm 0.05$ \\
\hline
\end{tabular}


